\title{
New insights into the phosphorylation of the threonine motif of the $\beta 1$ integrin cytoplasmic domain
}

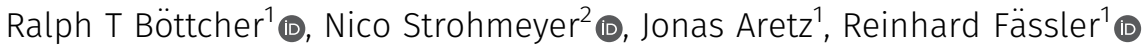

Integrins require an activation step before ligand binding and signaling that is mediated by talin and kindlin binding to the $\beta$ integrin cytosolic domain ( $\beta$-tail). Conflicting reports exist about the contribution of phosphorylation of a conserved threonine motif in the $\beta 1$-tail ( $\beta 1-p$ T788/pT789) to integrin activation. We show that widely used and commercially available antibodies against $\beta 1-p T 788 /$ pT789 integrin do not detect specific $\beta 1-p T 788 /$ pT789 integrin signals in immunoblots of several human and mouse cell lysates but bind bi-phosphorylated threonine residues in numerous proteins, which were identified by mass spectrometry experiments. Furthermore, we found that fibroblasts and epithelial cells expressing the phospho-mimicking $\beta 1-T T 788 / 789 D D$ integrin failed to activate $\beta 1$ integrins and displayed reduced integrin ligand binding, adhesion initiation and cell spreading. These cellular defects are specifically caused by the inability of kindlin to bind $\beta 1$-tail polypeptides carrying a phosphorylated threonine motif or phospho-mimicking TT788/ 789DD substitutions. Our findings indicate that the doublethreonine motif in $\beta 1$-class integrins is not a major phosphorylation site but if phosphorylated would curb integrin function.

DOI 10.26508/Isa.202101301 | Received 17 November 2021 | Revised 23 December 2021 | Accepted 23 December 2021 | Published online 7 January 2022

\section{Introduction}

Integrins are heterodimeric transmembrane proteins that mediate cell adhesion to extracellular matrix proteins. A feature of integrin function is the requirement of an activation step that is characterized by a reversible shift between unbound, low-affinity (inactive) and bound, high-affinity (active) conformations. Integrin activation is induced and/or maintained by the binding of the FERM (protein 4.1, ezrin, radixin, and moesin) domain-containing adaptor proteins talin and kindlin (Cluzel et al, 2005; Han et al, 2006; Moser et al, 2008; Ye et al, 2013; Theodosiou et al, 2016; Böttcher et al, 2017) to conserved NxxY motifs and adjacent residues in $\beta$-integrin cytoplasmic domains ( $\beta$-tail). The association of the $\beta$-tail with talin and kindlin is regulated by signals that control their activation state (termed inside-out signaling). Alternatively, the tyrosine and threonine residues of $\beta$-tails (Fig 1A) can be phosphorylated, which alters the affinity for talin and kindlin and the competitive inactivators such as filamin-A and L-plastin (LCP1) (Hynes, 2002; Tseng et al, 2018; Gahmberg et al, 2019). The phosphorylation of the tyrosine residues in the NxxY motifs of the $\beta 1$-tail is mediated by Src (Hirst et al, 1986; Johansson et al, 1994) resulting in reduced talin and kindlin binding (Anthis et al, 2009; Meves et al, 2011). Interestingly, phosphorylation of either or both tyrosines is dispensable for homeostasis (Chen et al, 2006; Czuchra et al, 2006) but important for enabling anchorage-independent cancer cell growth (Plantefaber \& Hynes, 1989; Sakai et al, 2001; Pylayeva \& Giancotti, 2006). In the case of the $\beta 1$-tail threonine phosphorylation, both the identity of the kinase as well as the functional consequences of the phosphorylation event are less investigated and hence, less clear.

Almost all integrin $\beta$ subunits (T788/T789 in the human and mouse $\beta 1$ integrin) harbor an evolutionary conserved doublethreonine motif, which is located membrane proximally to the NxxY motif that recruits kindlin and filamin-A to $\beta$-tails (GarciaAlvarez et al, 2003; Kiema et al, 2006; Wegener et al, 2007; Moser et al, 2008; Gingras et al, 2009; Böttcher et al, 2012; Liu et al, 2015). The phosphorylation of the double threonine motif in the $\beta 1$-tail was shown to modulate integrin function, although with conflicting consequences. Structural and biochemical studies suggested that the phosphorylation of the double-threonine motif increases integrin activity (Fagerholm et al, 2005; Takala et al, 2008; Craig et al, 2009; Rehberg et al, 2014; Grimm et al, 2020) by decreasing filamin-A and increasing kindlin binding (Chatterjee et al, 2018; Grimm et al, 2020). On the other hand, the phosphorylation of the doublethreonine motif has also been associated with integrin inactivation, adhesion disassembly and the rounding up of mitotic cells (Suzuki \& Takahashi, 2003; Kim et al, 2004). The conflicting observations of the $\beta 1-\mathrm{T788} / \mathrm{T789}$ phosphorylation for integrin activity are not resolved and the kinase(s) that mediate(s) the $\beta 1$-T788/T789 phosphorylation have also not been identified. However, the phosphatases PP2A and PPM1F were shown to de-phosphorylate the phospho-threonine motif in $\beta 1$ integrin tails (Kim et al, 2004; Grimm et al, 2020). ${ }^{1}$ Department of Molecular Medicine, Max Planck Institute of Biochemistry, Martinsried, Germany ${ }^{2}$ Department of Biosystems Science and Engineering, Eidgenössische
Technische Hochschule Zurich, Basel, Switzerland

Correspondence: faessler@biochem.mpg.de 
A

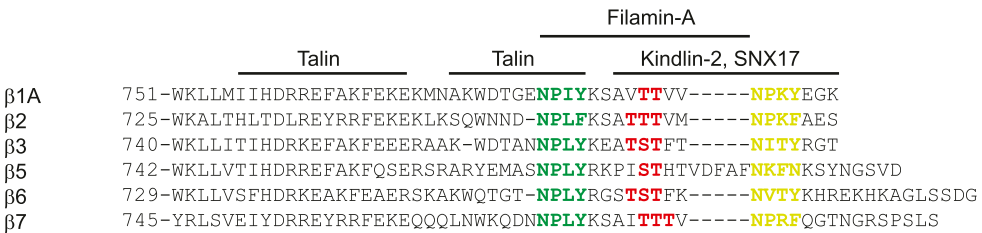

B

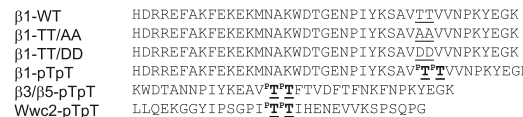

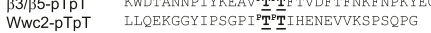

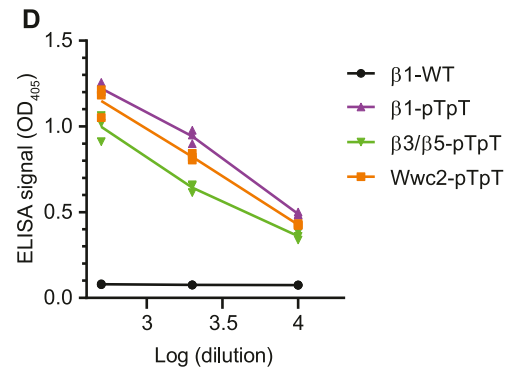

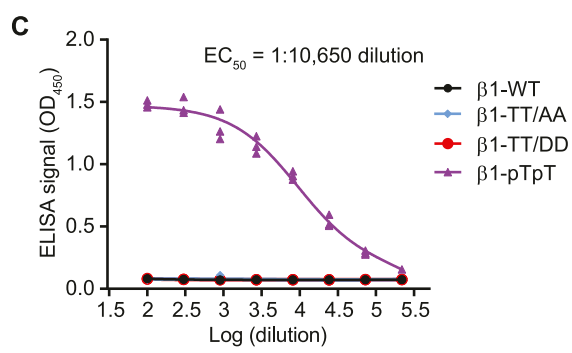

E

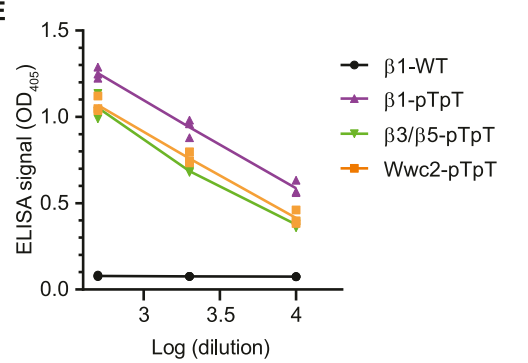

Figure 1. Specificity of the anti- $\beta 1-p T p T$ integrin antibody.

(A) Alignment of cytoplasmic amino acid residues of mouse integrin $\beta$ subunits. The conserved threonine motif (red), the proximal NPXY motif (green), the distal NxXY motif (yellow-green), and the binding sites of talin, kindlin-2, SNX17, and filamin-A are indicated. (B) Sequences of the synthetic peptides used to determine the specificity of the anti- $\beta 1$-pTpT antibodies by ELISA. (C) Affinity measurement of the anti- $\beta 1$-pTpT integrin antibody (Thermo Fisher Scientific) to the immobilized $\beta 1$-pTpT, $\beta 1$-TT/AA $\beta 1-T T / D D$, and $\beta 1-W T$ tail peptides. The dilution factor of the antibody used to generate the titration curve is indicated on the plot. The $\mathrm{EC}_{50}$ dilution is indicated. (D, E) Quantification of binding of the anti- $\beta 1-\mathbf{p T p T}$ integrin antibody (Thermo Fisher Scientific) (D) and anti- $\beta 1$ - $\mathbf{p T p}$ T integrin antibody (Abcam) (E) towards the indicated $\beta 1$ integrin tail and phosphorylated Wwc2 peptides. A dilution range between 1:500 and 1:10,000 of the antibodies was used.
In the present study, we studied the phosphorylation of the double threonine motif in $\beta 1$-tails in a range of human and mouse cell lines by immunostaining, immunoblotting and mass spectrometry using commercially available anti- $\beta 1-p T 788 / p T 789$ ( $\beta 1-p T p T)$ antibodies. We also determined the consequences of $\beta 1-\mathrm{T788} / \mathrm{T789}$ phosphorylation for kindlin and talin binding, cell adhesion and spreading. Our results suggest that the phosphorylation of the $\beta 1-T 788 / T 789$ motif is, if at all, a rare event that reduces kindlin recruitment to integrins, integrin activity, cell adhesion, and spreading.

\section{Results}

\section{The $\beta 1-T 788 /$ T789 phosphorylation in cell lines}

Changes in $\beta 1$-tail phosphorylation during spreading and mitosis have been analyzed with commercially available phosphorylationspecific antibodies (Suzuki \& Takahashi, 2003; Kim et al, 2004; Craig et al, 2009; Rehberg et al, 2014; Grimm et al, 2020). To test the specificity of two commercially available anti- $\beta 1$ integrin pT788/ pT789 ( $\beta 1$-pTpT) antibodies we established a direct ELISA using immobilized in-house synthesized $\beta 1$-tail peptides. The peptides were incubated with different concentrations of the anti- $\beta 1$-pTpT antibodies to obtain dose-response curves. Whereas the half maximal effective concentration $\left(E_{50}\right.$ ) of the anti- $\beta 1$-pTpT antibody was reached at a dilution of 1:10,650 for the $\beta 1$-pTpT peptide, dilutions of the anti- $\beta 1$-pTpT antibody up to 1:100 bound neither wild- type $\beta 1$ ( $\beta 1-W T)$ nor the phospho-mimicking $\beta 1-T T 788 / 789 D D(\beta 1-$ $\Pi T / D D)$ or the non-phosphorylatable $\beta 1-T 788 / 789 \mathrm{AA}$ ( $\beta 1-T \mathrm{~T} / \mathrm{AA})$ peptides pointing to a high specificity of the commercial antiserum towards the bi-phosphorylated $\beta 1$-pTpT cytosolic tails (Fig 1B and $\mathrm{C}$ ). However, we also detected binding of the two anti- $\beta 1-\mathrm{pT} T$ antibodies to chimeric $\beta 3 / \beta 5$-pTpT peptides and an unrelated peptide with a bi-phosphorylated double-threonine motif derived from the cytosolic scaffolding protein Wwc2 (Höffken et al, 2021) (Fig $1 D$ and E), indicating that the anti- $\beta 1-p T p T$ antibodies are not specific for $\beta 1$-pT788/pT789 but also react with phosphorylated bi-threonine motifs in $\beta 1$ integrin-unrelated proteins.

Next, we analyzed $\beta 1-p T 788 / p T 789$ levels with the anti- $\beta 1$-pTpT antibodies in lysates from spread interphase and mitotic mouse fibroblasts seeded on fibronectin (FN). To control the specificity of the immunosignal, we compared $\beta 1-p T 788 / p T 789$ signals in $\beta 1$ integrin knockout $(\beta 1-\mathrm{KO})$ fibroblasts, and wild-type $\beta 1$ integrin ( $\beta 1$-WT) and non-phosphorylatable $\beta 1$ integrin TT788/789AA ( $\beta 1-T T$ / AA) expressing fibroblasts. In line with previous reports (Suzuki \& Takahashi, 2003; Grimm et al, 2020), the anti- $\beta 1-p T p T$ antibodies from two different commercial sources detected a transiently upregulated protein with an apparent molecular weight of 125-130 kD, which corresponds to the apparent molecular weight of the mature $\beta 1$ subunit, in interphase fibroblasts seeded on FN or fibroblasts stalled in mitosis (Figs 2A and C and S1A). However, signals with same size and kinetics were also detected in $\beta 1-\mathrm{KO}$ and $\beta 1-\mathrm{TT} / \mathrm{AA}-$ expressing fibroblasts, suggesting that the anti- $\beta 1$-pTpT antibodies recognize $\beta 1$ integrin-unrelated protein(s). Moreover, the 125-130 kD signal was undetectable by anti- $\beta 1$-pTpT immunoblotting of $\beta 1$ integrin immunoprecipitates (IPS) obtained with a polyclonal rabbit 


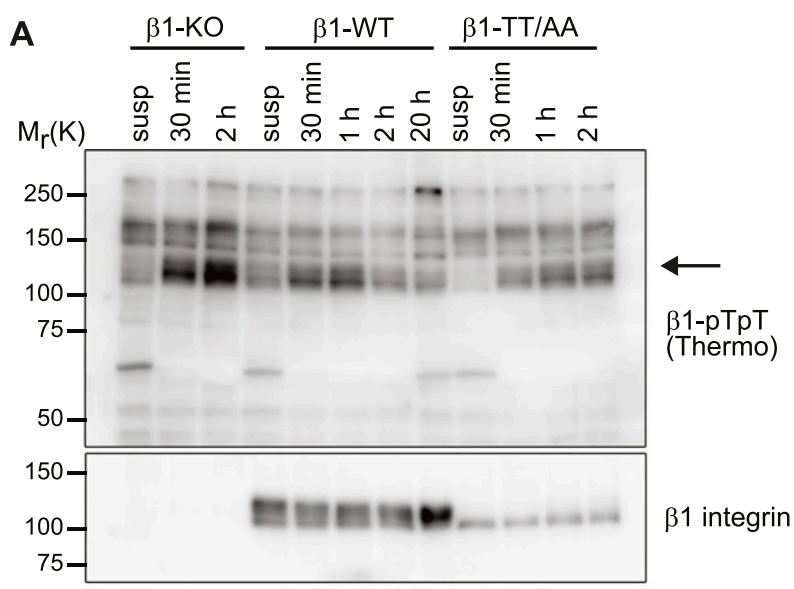

B
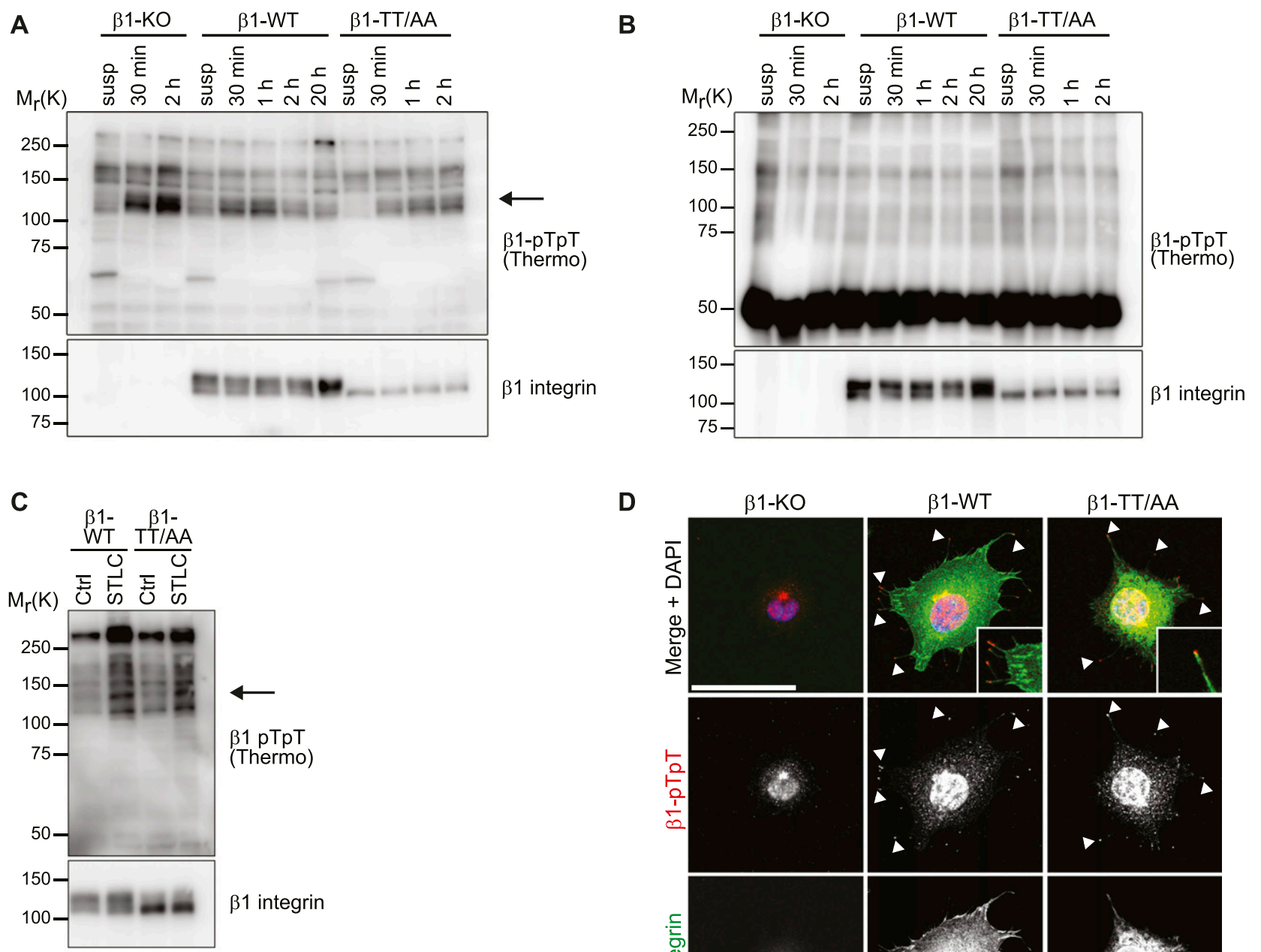

D
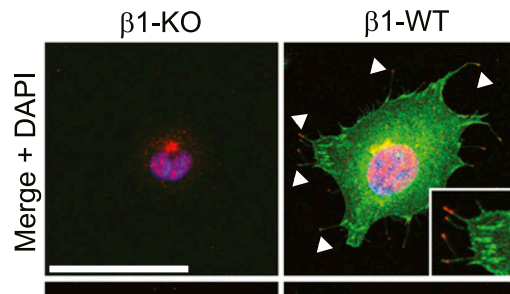

B1-TT/AA
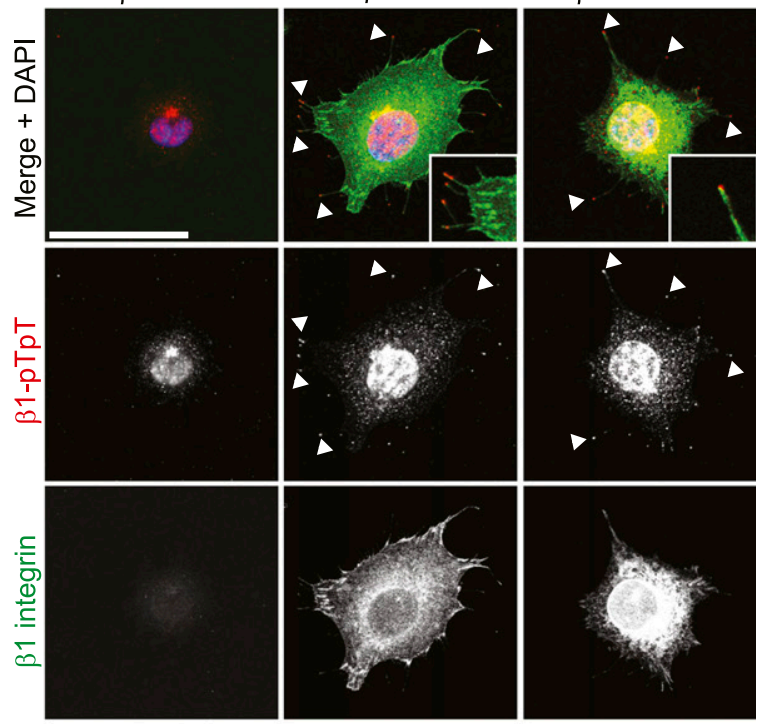

E
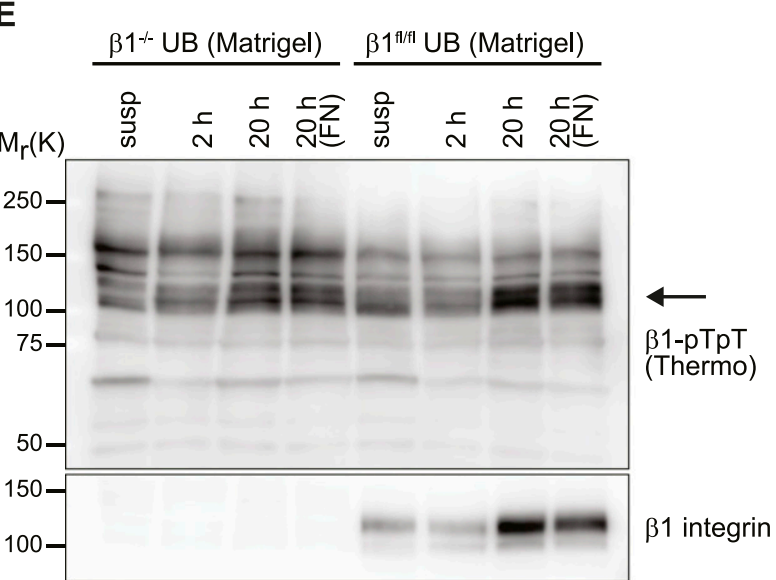

$\mathbf{F}$

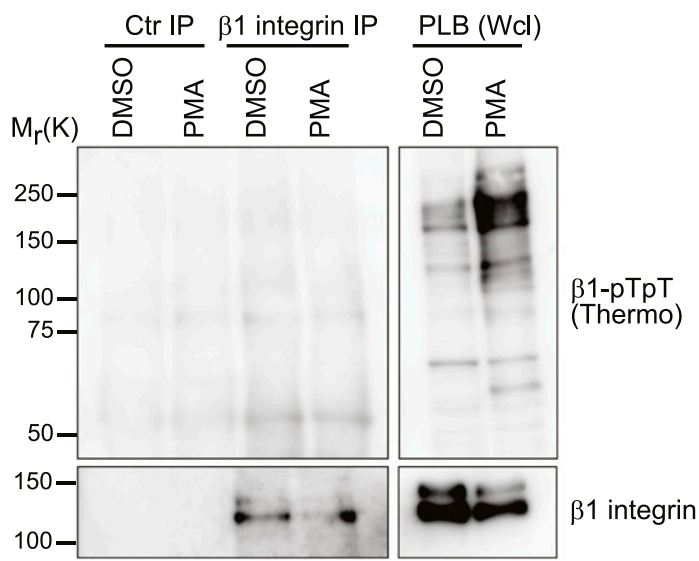

Figure 2. $\quad \beta 1$ integrin $7788 / 7789$ motif phosphorylation is not detectable.

(A, B) Western blot analysis of whole cell lysates (A) and $\beta 1$ integrin immunoprecipitations (B) of $\beta 1$-KO, $\beta 1$-WT, and $\beta 1$-TT/AA expressing fibroblasts kept in suspension (susp) or seeded on fibronectin for indicated times. Blots were probed with antibodies against $\beta 1$-pTpT integrin (Thermo Fisher Scientific) and total $\beta 1$ integrin. Arrow points toward transiently up-regulated protein with an apparent molecular weight of 125-130 kD. (C) Western blots of $\beta 1$-WT and $\beta 1$-TT/AA fibroblasts released from $6 \mathrm{~h}$ treatment with S-trityl-L-cysteine to enrich for mitotic cells or left untreated (Ctrl) and probed with antibodies against $\beta 1$-pTpT integrin (Thermo Fisher Scientific) and total $\beta 1$ integrin. Arrow points toward transiently up-regulated protein with an apparent molecular weight of 125-130 kD. (D) Fluorescence microscopy images of $\beta 1$-KO, 
anti-mouse $\beta 1$ integrin antiserum raised against the $\beta 1$ integrin ectodomain (Figs 2B and S1B), which further corroborates the notion that the commercial anti- $\beta 1$-pTpT antibodies do not detect the phosphorylated $\beta 1-T 788 /$ T789 motif in FN-seeded fibroblasts in immunoblots. To further validate $\beta 1$-tail threonine phosphorylation, we generated lysates from FN-seeded fibroblasts and performed immunoblotting with two commercial anti-phosphothreonine (anti-pT) antibodies. These antibodies should recognize all phosphorylated threonine residues, irrespective of the protein backbone. The anti-pT antibodies detected proteins with a molecular weight of 125-130 kD in $\beta 1$-WT- as well as in $\beta 1-K O-$ and $\beta 1-\mathrm{TT} / \mathrm{AA}$-expressing fibroblasts (Fig S1C and E). These unspecific signals were not detectable anymore with the anti-pT antibodies in immunoblots of IPs produced with the polyclonal anti-mouse $\beta 1$ integrin antiserum from $\beta 1-\mathrm{WT}-, \beta 1-\mathrm{KO}$-, and $\beta 1-\mathrm{TT} / \mathrm{AA}$-expressing cells (Fig S1D and F). Conversely, the polyclonal anti-mouse $\beta 1$ integrin antiserum was also not able to detect $\beta 1$ integrin signals in IPs produced with the anti-pT antibodies (Fig S1G and $\mathrm{H}$ and data not shown). Finally, we immunoblotted IPS from FN-seeded cells pre-treated with the PP2A inhibitor Calyculin A. The anti-pT antibody (Thermo Fisher Scientific) detected a band of $125-130 \mathrm{kD}$ in anti- $\beta 1$ integrin IPS. However, this band was present in both, $\beta 1-$ WT and $\beta 1-K O$ cells (Fig S1I and J). Together, these data indicate that under our experimental conditions $\beta 1$-T788/T789 phosphorylation is either not occurring or not detectable.

The immunostaining of $\beta 1$-WT expressing fibroblasts seeded for 40 min or $2 \mathrm{~h}$ on FN with anti- $\beta 1-$ pTpT and anti-pT antibodies produced signals in the nucleus and cytosol, but not in $\beta 1$ integrinpositive FAs of $\beta 1$-WT-expressing fibroblasts. One anti- $\beta 1-p T p T$ antibody (Abcam) produced signals at filopodia tips and along actin fibers in $\beta 1$-WT- as well as in $\beta 1-\mathrm{KO}-$ and $\beta 1-\mathrm{TT} / \mathrm{AA}$-expressing fibroblasts (Figs $2 \mathrm{D}$ and S2A-C).

We also performed mass spectrometry to identify $\beta 1$-pT788/ pT789 phosphorylation in $\beta 1$ integrin IPS obtained from $\beta 1$-WT interphase fibroblasts either kept in suspension or seeded for 45 and 90 min on FN, or $\beta 1$-WT fibroblasts arrested in mitosis with polyclonal rabbit anti-mouse $\beta 1$ integrin antiserum. Whereas the non-phosphorylated $\beta 1$-T788/T789-containing peptide was clearly detectable in the IPs, the phosphorylated $\beta 1$-pT788/pT789 peptides were neither found in $\beta 1$-WT interphase nor in mitotically arrested fibroblasts (Fig S3A). Also the enrichment of $\beta 1-p T 788 / p T 789$ integrin in FN-seeded $\beta 1$-WT fibroblasts by immunoprecipitation with anti- $\beta 1$-pTpT antibodies followed by tandem mass spectrometry (MS/MS) revealed that $\beta 1$-T788/T789-containing peptides were not among the 181 proteins that were minimally threefold enriched in $\beta 1$-pTpT IPS over control IgG IPS (Fig S3B and C).

To confirm our findings also in epithelial and hematopoietic cells, we immunoblotted whole cell lysates from mouse ureteric bud (UB) epithelial cells, mouse macrophage line RAW 264.7 and the acute myeloid leukemia cell line PBL-985 with the commercial anti- $\beta 1$-pTpT antibodies. The UB cells were established from UBs isolated from mouse embryos carrying floxed Itgb1 alleles $\left(\beta 1^{\mathrm{fl} / \mathrm{fl}} \mathrm{UB}\right)$ and subsequently transduced with $C r e$ to generate $\beta 1^{-/-}$UB cells. The endogenous wild-type $\beta 1$ integrin expressing $\beta 1^{\mathrm{fl} / \mathrm{fl}} U \mathrm{~B}$ and $\beta 1^{-1-} \cup B$ cells seeded for different times on Matrigel displayed a similar transient increase in an apparent molecular weight protein of 125-130 kD with the anti- $\beta 1-p T p T$ antibodies as observed in fibroblasts, indicating that the immunosignal produced by the anti$\beta 1$-pTpT antibodies is also unspecific in the UB epithelial cells (Fig 2E). The RAW 264.7 and PLB-985 cell lines were analyzed before and after stimulation with phorbol 12-myristate 13-acetate (PMA), which was shown to induce the phosphorylation of the threonine motif in the $\beta 2$-tail (Fagerholm et al, 2002; Hilden et al, 2003; Nurmi et al, 2006; Takala et al, 2008). Although the PMA treatment increased the signal intensity of multiple protein bands that were detected with the anti- $\beta 1$-pTpT integrin antibody, none were detected in $\beta 1$ integrin IPs indicating that $\beta 1-T 788 / T 789$ phosphorylation is, if it was induced at all, below the detection limit of these commercial anti- $\beta 1$-pTpT antibodies (Figs 2F and S2D).

To rule out that high levels of the PPM1F phosphatase cause the loss of $\beta 1$-T788/T789 phosphorylation, we analyzed the $\beta 1-T 788 /$ T789 phosphorylation in A172 PPM1F knockout cells (Grimm et al, 2020). The experiments revealed comparable anti- $\beta 1-p T p T$ signals in Western blots of suspended or FN-seeded WT and PPM1Fdeficient A172 cells. Furthermore, these immunosignals were undetectable in $\beta 1$ integrin IPs (Fig S2E), which altogether indicates that $\beta 1-$ T788/T789 phosphorylation is either below the detection limit or absent in all cell lines tested.

\section{The phosphorylated integrin $\beta 1-T 788 / T 789$ motif fails to bind kindlin and SNX17}

The $T 788 / T 789$ motif of the $\beta 1$-tail is involved in binding several cytoplasmic proteins including kindlin, SNX17, and filamin-A (Fig 1A). To explore the consequences of $\beta 1-T 788 /$ T789 phosphorylation for kindlin-2 binding, we tested whether synthetic peptides representing the cytoplasmic domains of $\beta 1$-WT, $\beta 1$-TT/AA, $\beta 1$-pTpT, $\beta 1$ TT/DD, or scrambled peptides are able to pull down recombinant kindlin-2 and talin-1 head domain (THD). Expectedly, the THD was pulled down with all $\beta 1$-tail peptides (Fig $3 \mathrm{~A}$ and B). In contrast, recombinant kindlin-2 was only pulled down with $\beta 1$-WT but not with $\beta 1-\mathrm{TT} / \mathrm{AA}, \beta 1-\mathrm{TT} / \mathrm{DD}$, and $\beta 1-\mathrm{pTpT}$, irrespective whether THD was absent or present in the pull-down assays (Fig $3 A$ and B). Whereas affinity measurements using microscale thermophoresis (MST) revealed similar affinities of THD for phospho-inhibitory, phospho-mimicking, or phosphorylated $\beta 1-T 788 / T 789$ tail peptides as for $\beta 1$-WT tails, the affinity of kindlin-2 for $\beta 1-T T / A A$ was strongly reduced and for $\beta 1-T T / D D$ and $\beta 1$-pTpT not measurable anymore (Fig 3C). Expectedly, disruption of the membrane-proximal

$\beta 1-W T$, and $\beta 1$-TT/AA expressing fibroblasts seeded for 40 min on fibronectin with antibodies against $\beta 1$-pTpT integrin (Abcam, red) and total $\beta 1$ integrin (green). Arrowheads indicate filopodia tips. DAPI was used to stain nuclei. Bar, $20 \mu \mathrm{m}$. (E) Western blot analysis of wild-type $\beta 1$ integrin expressing $\beta 1^{\text {fl/fl }}$ ureteric bud epithelial cells and $\beta 1^{-1-}$ ureteric bud cells kept in suspension (susp) or seeded on Matrigel for indicated times. Blots were probed with antibodies against $\beta 1$-pTpT integrin (Thermo Fisher Scientific) and total $\beta 1$ integrin. Arrow points toward transiently up-regulated protein with an apparent molecular weight of $125-130$ kD. (F) Western blot analysis of whole cell lysates and $\beta 1$ integrin immunoprecipitations of PLB-985 (human AML cell line) cells treated for 30 min at $37^{\circ} \mathrm{C}$ with $100 \mathrm{ng} / \mathrm{ml}$ PMA or left unstimulated (DMSO). Blots were probed with antibodies against $\beta 1$-pTpT integrin and total $\beta 1$ integrin. Ctr IP, unrelated rabbit antibody. 

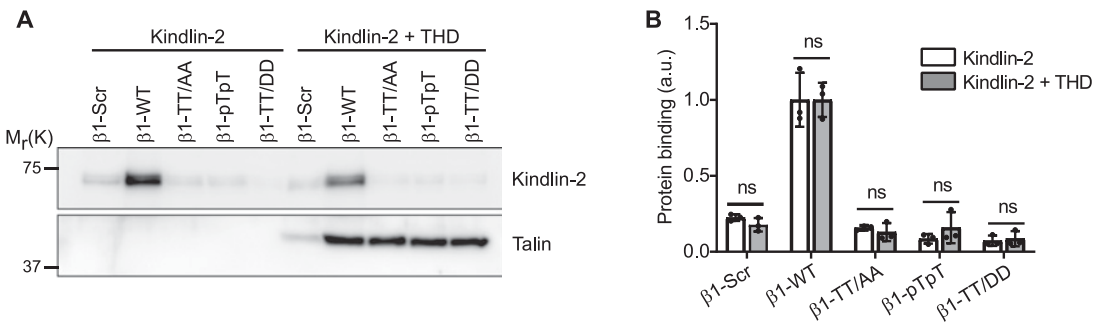

C

\begin{tabular}{ccc}
$\beta 1$-tail peptide & $\mathrm{K}_{\mathrm{d}, \text { THD }}(\mu \mathrm{M})$ & $\mathrm{K}_{\mathrm{d} \text {,kindin-2 } 2}(\mu \mathrm{M})$ \\
\hline$\beta 1-\mathrm{WT}$ & $140 \pm 20$ & $2.9 \pm 0.2$ \\
$\beta 1-\mathrm{TT} / \mathrm{AA}$ & $100 \pm 15$ & $151 \pm 1$ \\
$\beta 1-\mathrm{TT} / \mathrm{DD}$ & $170 \pm 40$ & $\mathrm{NB}$ \\
$\beta 1$ - $\mathrm{PTPT}$ & $140 \pm 40$ & $\mathrm{NB}$ \\
$\beta 1-\mathrm{Y} 783 \mathrm{~A}$ & $\mathrm{NB}$ & $4.9 \pm 0.7$
\end{tabular}

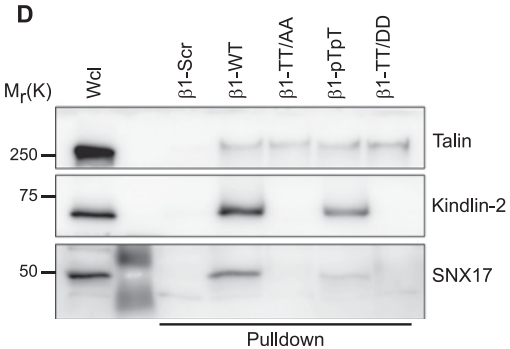

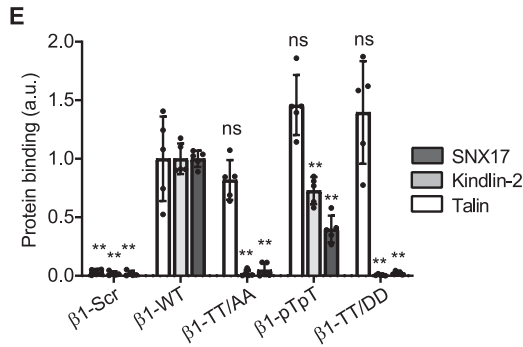

Figure 3. $\beta 1$ integrin $7788 / T 789$ phosphorylation curbs kindlin-2 and SNX17 but not talin binding. (A) Streptavidin-bead pull-down assay with the indicated biotinylated $\beta 1$-integrin cytoplasmic tail ( $\beta 1$-tail) peptides and recombinant kindlin-2, or a combination of kindlin-2 and talin head domain. After pull-down, bound proteins were detected by Western blotting. (B) Densitometric analysis of kindlin-2 binding to indicated $\beta 1$-tail peptides in the absence and presence of talin head domain. Data are mean \pm SD . $n=3$. ns, not significant (Mann-Whitney $U$ test). (C) Affinities of talin and kindlin-2 for indicated Atto488labeled $\beta 1$-tail peptides determined by microscale thermophoresis. (D) Indicated biotinylated $\beta 1$-tail peptides were analyzed for binding to endogenous talin, kindlin-2, and SNX17 by Western blotting. Wcl, whole cell lysate. (E) Densitometric analysis of talin, kindlin-2, and SNX17 to the indicated $\beta 1$-tail peptides. Data are mean \pm SD of $n=5$ independent experiments. $\star \star P<0.01 ;$ ns, not significant (Mann-Whitney $U$ test). Statistical significances are calculated between $\beta 1$-WT and mutant $\beta 1$-tail peptides.
NPXY motif ( $\beta 1$-Y783A) abolished THD binding without influencing the affinity of kindlin-2 (Fig 3C).

Pull-down experiments of whole cell lysate showed that talin efficiently bound to all $\beta 1$-tail peptides tested, whereas kindlin-2 and SNX17 readily bound to $\beta 1-W T$, their binding to the $\beta 1$-pTpT peptide was reduced to $27 \pm 11 \%$ and $60 \pm 11 \%$ (mean $\pm S D, n=5$ ), respectively, and lost to $\beta 1-\mathrm{TT} / \mathrm{AA}, \beta 1-\mathrm{TT} / \mathrm{DD}$, and the scrambled peptides (Fig 3D and E). Interestingly, mass spectrometry-based measurements of the phosphorylation state of the $\beta 1$-pTpT peptide revealed that their incubation in whole cell lysates reduced their phosphorylation by around $40 \%$, despite the presence of phosphatase inhibitors (see the Materials and Methods section), which explains the decreased binding to kindlin-2 and SNX17. Altogether these findings suggest that phosphorylation of the doublethreonine motif in $\beta 1-T 788 / T 789$ blocks kindlin-2 and SNX17 binding to $\beta 1$ integrins.

\section{$\beta 1-T T / D D$ and $\beta 1-T T / E E$ substitutions curb integrin activation and ligand binding}

To investigate the potential role of the phosphorylation of $\beta 1$-T788/ T789 for $\beta 1$ integrin activation and function in cells, we re-expressed comparable levels of $\beta 1-\mathrm{TT} / \mathrm{DD}$ and $\beta 1-\mathrm{TT} / \mathrm{EE}$, or $\beta 1-\mathrm{TT} / \mathrm{AA}$ in $\beta 1$ integrin-deficient fibroblasts $(\beta 1-K O)$. In addition, we expressed $\beta 1-Y 783 A$, which disrupts the membrane-proximal NPXY motif required for talin and filamin-A binding, and $\beta 1-Y 795 A$, which disrupts the membrane-distal NxxY motif required for kindlin and SNX17 binding. Flow cytometry (FC) measurements and immunostainings revealed reduced levels of the conformation-specific $\beta 1$ integrin activation epitope $9 \mathrm{EG} 7$ on the surface or in FAs of FN-seeded $\beta 1-\mathrm{KO}$ fibroblasts reconstituted with $\beta 1-Y 795 \mathrm{~A}, \beta 1-\mathrm{TT} / \mathrm{AA}, \beta 1-\mathrm{TT} / \mathrm{DD}$, and $\beta 1-T T / E E$ (Figs $4 A-C$ and $S 4$ ), indicating that the double-threonine substitution with either phospho-mimicking or phospho-inhibitory residues reduces integrin activity in fibroblasts.

Next, we investigated the consequences of altered $\beta 1$ integrin activity by characterizing the binding probabilities of $\beta 1-\mathrm{KO}$ fibroblasts reconstituted with $\beta 1-\mathrm{WT}, \beta 1-\mathrm{TT} / \mathrm{AA}, \beta 1-\mathrm{TT} / \mathrm{DD}$, and $\beta 1-\mathrm{TT} /$ EE by atomic force microscopy (AFM)-based single-cell force spectroscopy (SCFS) at molecular resolution (Fig S5A-D). We attached single fibroblasts to concanavalin A-coated cantilevers, approached them to FN fragments containing or lacking the RGD motif (FNIII7-10 RGD or FNIII7-10 ${ }^{\triangle R G D}$ ) until a contact force of $200 \mathrm{pN}$ was reached, maintained the cantilever at a constant height for 250 $\mathrm{ms}$, and subsequently retracted the fibroblast from the substrate. This resulted in a total contact time of $\sim 300 \mathrm{~ms}$, which is sufficient for $\alpha 5 \beta 1$ integrins to bind ligand (Benito-Jardón et al, 2020). We blocked the contribution of $\alpha \mathrm{v}$-class integrins to the binding probability by adding $1 \mu \mathrm{M}$ cilengitide to the medium. All tested fibroblast cell lines showed similar background binding probabilities to integrin-binding deficient FNIII7-10 ${ }^{\triangle R G D}$. Whereas cilengitide-treated $\beta 1-K O$ fibroblasts also showed background binding probability to FNIII7-10 RGD, cilengitide-treated $\beta 1-K O$ fibroblast reconstituted with $\beta 1-\mathrm{TT} / \mathrm{AA}, \beta 1-\mathrm{TT} / \mathrm{DD}$, and $\beta 1-\mathrm{TT} / \mathrm{EE}$ exhibited reduced integrin-specific binding probabilities to FNIII7-10 RGD compared with $\beta 1-W T$ expressing fibroblasts (Fig 4D). The $\beta 1-W T, \beta 1-T T / A A, \beta 1-T T / D D$, and $\beta 1-T T / E E$ expressing fibroblasts showed more than one unbinding event in $<3 \%$ of binding probability experiments on FNIII7-10 $\triangle \mathrm{RGD}$, whereas $\beta 1-W T$ fibroblasts exhibited multiple unbinding events (up to five) FNIII7-10 RGD in $32.3 \pm 19.5 \%$ (mean \pm SD,$n=9$ cells), which indicates that $\sim 300 \mathrm{~ms}$ 


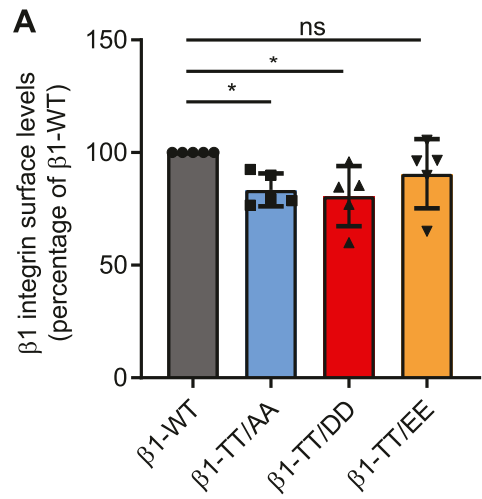

D

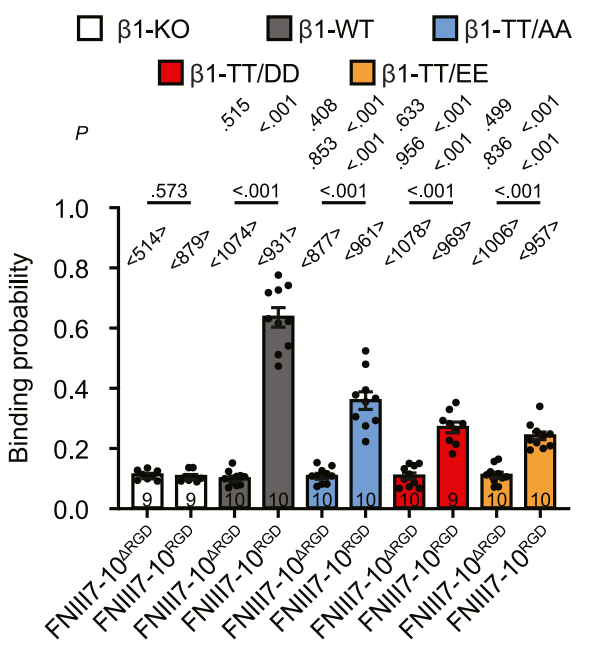

$\mathbf{F}$
B

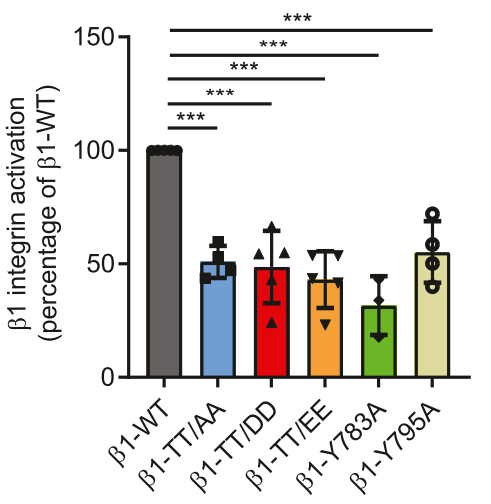

E

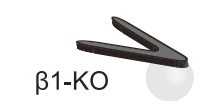

C
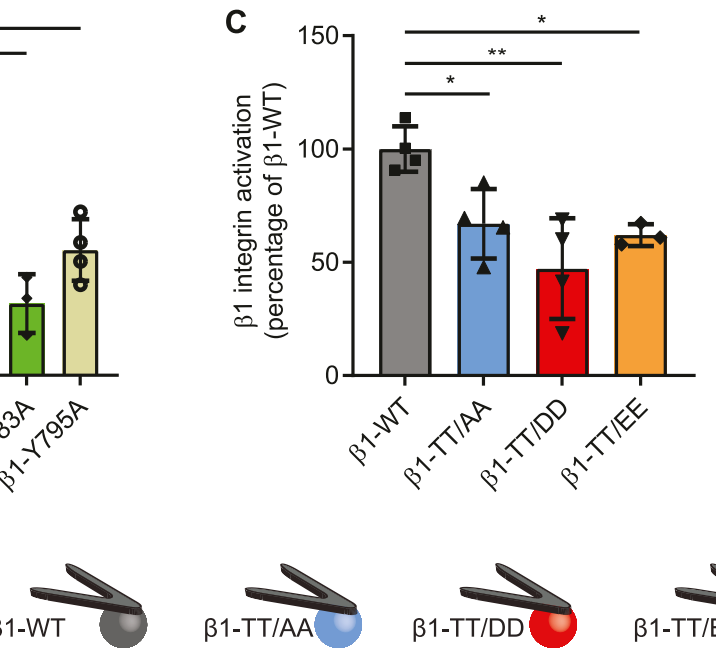

B1-TT/EE

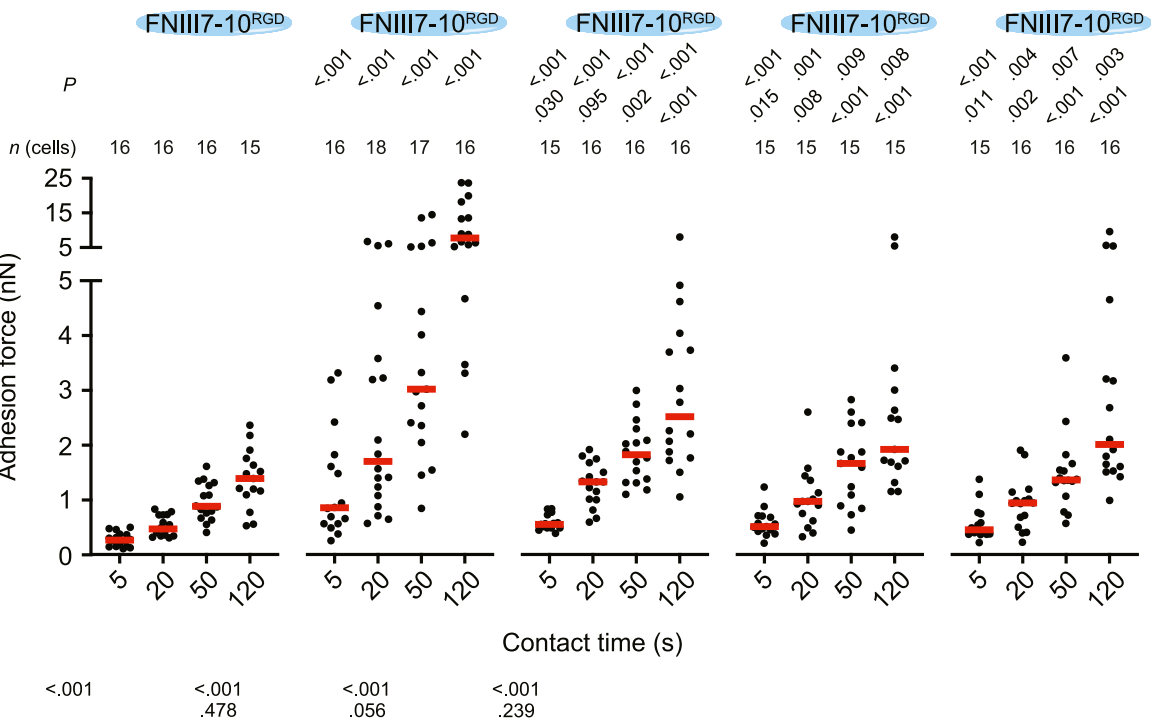

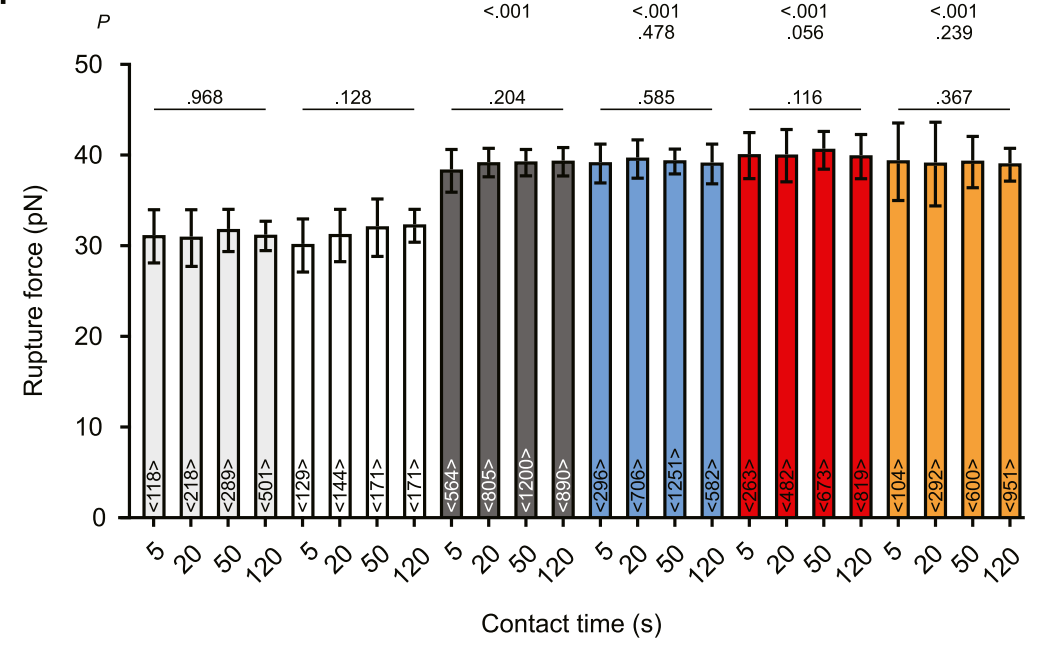

$\square \beta 1-K O$ on FNIII7-10 $\triangle$ RGD

$\square \beta 1-K O$ on FNIII7-10 RGD

$\square \beta 1-W T$ on FNIII7-10RGD

$\square \beta 1-T T / A A$ on FNIII7-10 RGD

$\beta 1-T T / D D$ on FNIII7-10 RGD

$\beta 1-\mathrm{TT} / \mathrm{EE}$ on FNIII7-10 RGD

Contact time (s)

Figure 4. Substitutions of threonine residues in the $\beta 1$ integrin cytoplasmic domain reduce integrin activation and functions.

(A) Quantification of cell surface expression of $\beta 1$ integrin on $\beta 1$-KO fibroblasts and $\beta 1$ integrin re-expressing fibroblasts measured by flow cytometry. The integrin levels were normalized to the levels on WT fibroblasts. Data are mean \pm SD. $n=5 .{ }^{*} P<0.05$; ns, not significant (one-way ANOVA with Kruskal-Wallis test). Statistical significances are calculated between $\beta 1$-WT and mutant cell lines. (B) Quantification of $\beta 1$ integrin activation on the indicated fibroblast cell lines measured by $9 \mathrm{EG} 7$ binding by flow cytometry analysis and corrected for total $\beta 1$ integrin levels. Data are mean \pm SD. $n=3-5$. ${ }^{* \star} P<0.001$ (one-way ANOVA). Statistical significances are calculated between $\beta 1$-WT and mutant cell lines. (C) Quantification of active $\beta 1$ integrin (9EG7) and total $\beta 1$ integrin levels by immunostaining of the indicated fibroblast cell lines after seeding on fibronectin-coated dishes for 40 min. Data are mean \pm SD. $n=4$ ( $n=3$ for TT/EE). ${ }^{*} P<0.01$; ${ }^{*}<<0.05$ (one-way ANOVA). Statistical significances are calculated between 
is sufficient for multiple integrins to bind ligand (Fig S5E and F). In line with reduced binding probability, all the $\beta 1$ integrins carrying TT-substitutions reduced the probability of multiple integrin binding within the chosen contact time ( $\beta 1-\mathrm{TT} / \mathrm{AA}: 7.7 \pm 4.0 \% ; \beta 1-\mathrm{TT} /$ EE: $4.6 \pm 4.1 \%$; $\beta 1-T T / D D: 3.8 \pm 3.2 \%$; all $P<0.001$ and $n=10$ cells). Altogether, the SCFS results show that the phospho-inhibitory $\beta 1-T T / A A$ as well as the phospho-mimicking $\beta 1-T T / D D$ or $\beta 1-T T /$ EE substitutions drastically reduce the binding rate of $\beta 1$-class integrins to $\mathrm{FN}$.

\section{$\beta 1-T T / D D$ and $\beta 1-T T / E E$ substitutions reduce cell adhesion and spreading}

Next, we investigated the adhesion strengthening of $\beta 1-K O$ fibroblasts expressing $\beta 1-W T, \beta 1-T T / A A, \beta 1-T T / D D$, and $\beta 1-T T / E E$ to FN in the presence of cilengitide by quantifying their adhesion forces to FNIII7-10 RGD at contact times ranging from 5 to $120 \mathrm{~s}$ (Figs 4E and S5G). In line with previous reports (Bharadwaj et al, 2017; BenitoJardón et al, 2020), fibroblasts expressing $\beta 1-W T$ integrins rapidly strengthened adhesion, which was quantified as the slope of a linear fit through all adhesion forces obtained from indicated contact times (Fig S5H). In contrast, fibroblasts expressing $\beta 1-T T / A A$, $\beta 1-T T / D D$, and $\beta 1-T T / E E$ established markedly reduced adhesion forces and adhesion strengthening to FNIII7-10 RGD. To determine the impact of the TT substitutions on the maximum force single $\beta 1$-integrins can bear before they detached from their ligands, we quantified single-rupture forces from force distance (FD) curves (Fig 4F). Whereas $\beta 1-\mathrm{KO}$ fibroblasts showed non-specific single-rupture forces from FNIII7-10 RGD and FNIII7-10 ${ }^{\triangle R G D}$ at all contact times, $\beta 1-\mathrm{WT}, \beta 1-\mathrm{TT} / \mathrm{AA}, \beta 1-\mathrm{TT} / \mathrm{DD}$, and $\beta 1-\mathrm{TT} / \mathrm{EE}$ expressing fibroblasts exhibited similar single-rupture forces from FNIII7-10 RGD that were contact time-independent and higher compared with $\beta 1-K O$ fibroblasts. These results show that single FN-bound $\beta 1$-integrins can bear similar forces irrespective of the TT-substitution, whereas their ability to strengthen adhesion is dramatically reduced.

Plate-and-wash assays on FN in the presence of cilengitide revealed diminished adhesion of $\beta 1-\mathrm{TT} / \mathrm{AA}, \beta 1-\mathrm{TT} / \mathrm{DD}$, and $\beta 1-\mathrm{TT} / \mathrm{EE}$ expressing fibroblast to FN $15 \mathrm{~min}$ and to a lesser extent $45 \mathrm{~min}$ after seeding when compared with $\beta 1$-WT fibroblasts, which was most pronounced for the $\beta 1-T T / D D$-expressing fibroblasts (Fig 5A and B). spreading of $\beta 1-T T / A A, \beta 1-T T / D D$, and $\beta 1-T T / E E$ expressing fibroblast on FN for 40 min or $4 \mathrm{~h}$ in the presence of cilengitide was also significantly impaired compared with $\beta 1$-WT cells (Fig 5C-E) with the strongest defect in $\beta 1-T T / D D$ fibroblasts.
To confirm these findings in epithelial cells, we generated $\beta 1$ integrin-deficient mouse $\beta 1^{-/}$UB cells rescued with $\beta 1-\mathrm{WT}, \beta 1-\mathrm{TT} /$ $\mathrm{AA}, \beta 1-\mathrm{TT} / \mathrm{DD}, \quad \beta 1-\mathrm{TT} / \mathrm{EE}$, and the talin- and kindlin-bindingdeficient $\beta 1-Y 783 A$ and $\beta 1-Y 795 A$, respectively. Irrespective of the integrin tail mutation, the UB cells displayed reduced total $\beta 1$ integrin and reduced 9EG7 epitope levels on their surface (Fig 5F and G). Furthermore, all $\beta 1$-tail mutant expressing UB cell lines almost completely failed to adhere to Matrigel (Fig $5 \mathrm{H}$ ). Thus, the adhesion inhibiting effect of the $\beta 1-\mathrm{TT} / \mathrm{AA}, \beta 1-\mathrm{TT} / \mathrm{DD}$, and $\beta 1-\mathrm{TT} / \mathrm{EE}$ mutations is not limited to fibroblasts but is also observed in epithelial cells, which altogether indicates that phospho-mimicking as well as phospho-inhibiting substitutions of the $\beta 1-T 788 / T 789$ curb integrin activation, cell adhesion and spreading.

\section{Discussion}

In the present article, we investigated the role of the conserved integrin threonine motif in the $\beta 1$-tail for integrin activation and function. We report that $\beta 1$-integrin phosphorylation at T788/T789 is below detection level in five cell lines analyzed, in vitro phosphorylated $\beta 1-T 788 / T 789$ tail peptides fail to bind kindlin-2, and phospho-mimicking $\beta 1$-TT788/789DD integrin expressing cells show reduced $\beta 1$ integrin activation, adhesion and spreading.

The phosphorylation of the conserved double-threonine motif in integrin $\beta 1$ tails has been investigated in several laboratories using commercial antibodies that were raised in rabbits against a chemically synthesized phosphopeptide derived from the $\beta 1$ integrin tail region containing pT788/pT789 (Suzuki \& Takahashi, 2003; Kim et al, 2004; Bhalla et al, 2009; Craig et al, 2009; Rehberg et al, 2014; Grimm et al, 2020). We established a sensitive ELISA assay, which confirmed that two commercial anti- $\beta 1$-pTpT antibodies bind to synthetic bi-phosphorylated $\beta 1-$ pTpT cytoplasmic tail peptides. However, this assay also showed binding of the antibodies to different integrin $\beta$-subunits and an unrelated bi-phosphothreonine containing peptide. In line with the binding to phosphorylated double-threonine motifs unrelated to the $\beta 1$-tail, the anti- $\beta 1$-pTpT antibodies also detected protein(s) with an apparent molecular weight of 120-130 kD in cell lysates, which-although corresponding to the molecular weight range of the mature $\beta 1$-integrin subunit-was also visible in $\beta 1$ integrin-deficient cells. Our mass spectrometry analysis of anti- $\beta 1$-pTpT IPS did not detect $\beta 1$ integrin tail peptides. Interestingly, however, we identified several proteins with an apparent molecular weight of 120-130 kD, including Wwc2, Tcof1, and Larp1, which could be the source of the

B1-WT and mutant cell lines. (D) Binding probabilities of the indicated fibroblast cell lines quantified by single-cell force spectroscopy after contact with FNIII7-10 ${ }^{\text {RGD }}$ or

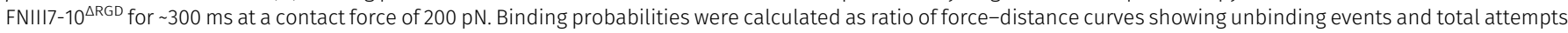
Dots represent binding probabilities of single fibroblasts, bars the mean and the error bars the SEM. 9-10 cells analyzed. Top row of $P$-values compare the given condition with $\beta 1$-KO fibroblasts on the respective substrate, lower row of $P$-values compare given condition with $\beta 1$-KO fibroblasts re-expressing $\beta 1$-WT. $P$-values on bars compare binding probabilities of given cell line to FNIII7-10 RGD and FNIII7-10 ${ }^{\triangle R G D}$. (E) Adhesion forces of single fibroblasts to FNIII7-10 RGD after given contact times. Dots represent adhesion forces of single fibroblasts $(n=15-18)$, red bars their mean. Top row of $P$-values compares adhesion forces of given fibroblast line to adhesion forces of $\beta 1$-KO fibroblasts and lower row of $P$-values to adhesion forces to $\beta 1$ WT fibroblasts. (F) Rupture forces of single unbinding events were analyzed from force-distance curves of adhesion force experiments, data taken from (E) and Fig S5G. Bars display the median rupture force for the given cell line and contact time, the error bars the $95 \%$ confidence interval of the median and $<n>$ the number of rupture events analyzed. $P$-values on bars show statistically significant differences between rupture forces after different contact times for given cell line and condition. $P$-values compare rupture forces of given condition with rupture forces of $\beta 1$-KO fibroblasts (top row) or $\beta 1$-WT fibroblasts (bottom row) on FNIII7-10 RGD 
A

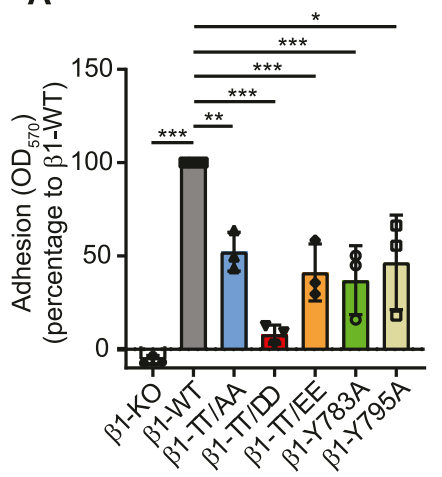

B

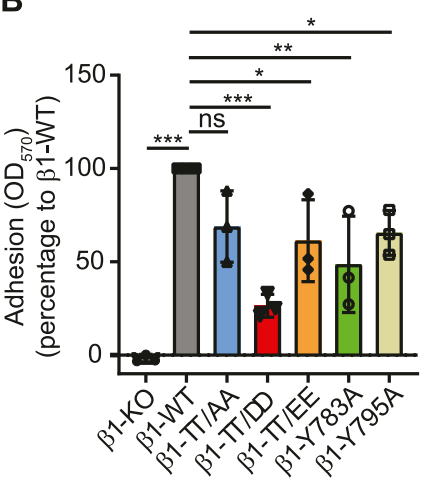

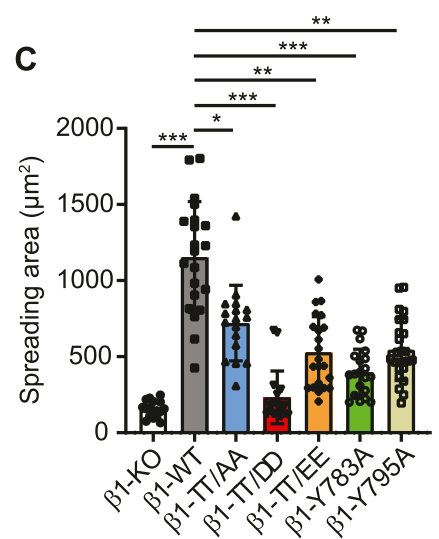

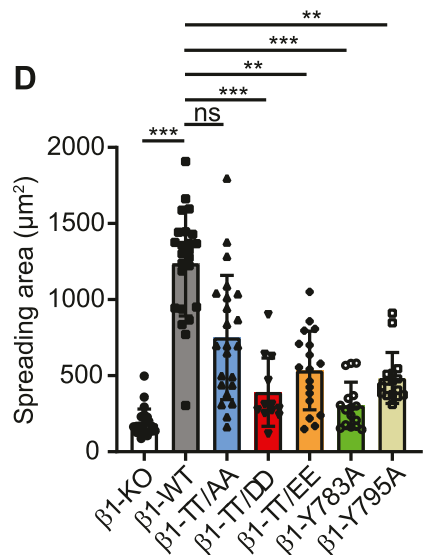

E

E $\quad \beta 1-\mathrm{KO}$

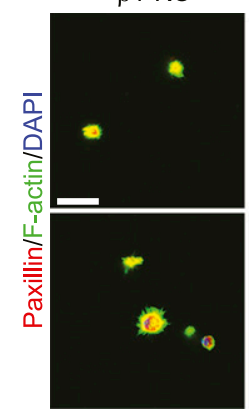

$\beta 1-W T$

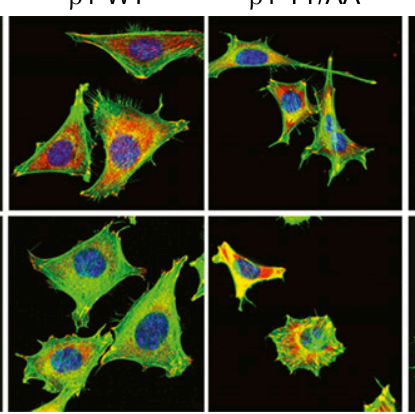

$\beta 1-T T / D D$

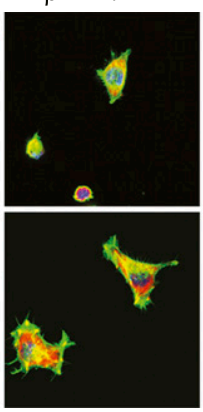

$\beta 1$-TT/EE

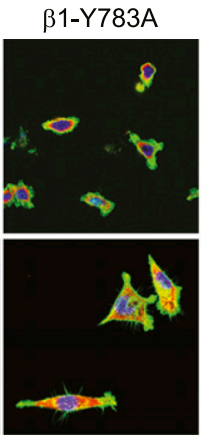

$\beta 1-Y 795 A$
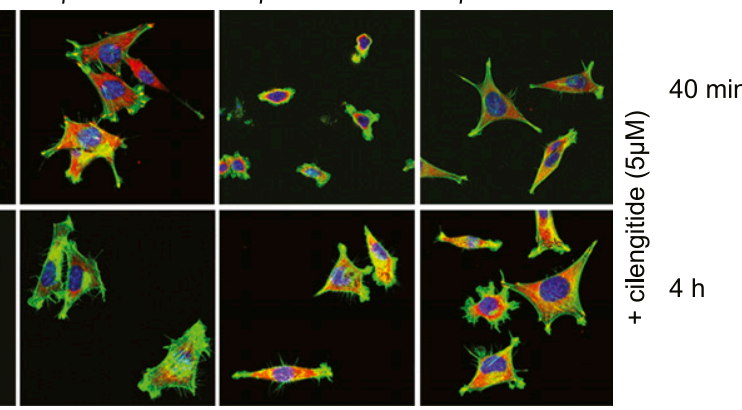

F

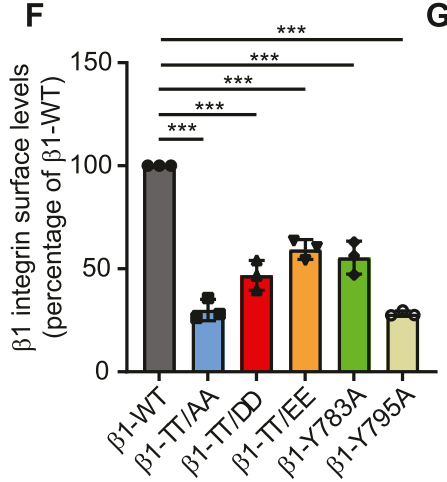

G

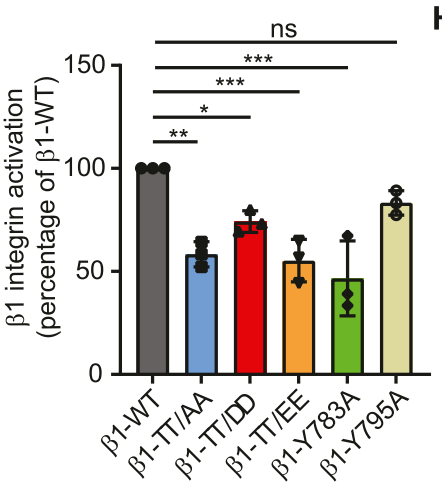

H

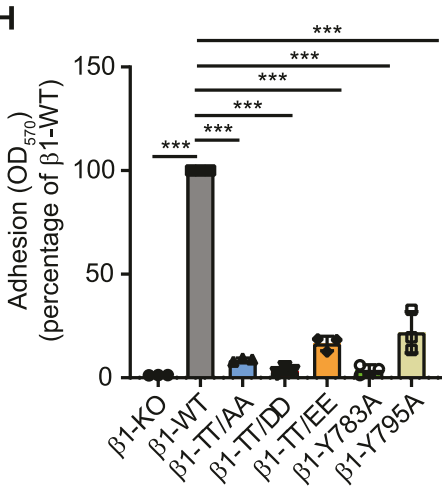

Figure 5. $\quad \beta 1$ integrin TT/DD and TT/EE inhibit cell adhesion and spreading.

(A, B) Quantification of cell adhesion on fibronectin (FN) 15 min (A) and 40 min (B) after seeding serum-starved fibroblasts in the presence of $5 \mu$ M cilengitide. Data are mean \pm SD. $n=3 .{ }^{* *} P<0.001 ;{ }^{* *} P<0.01 ;{ }^{*} P<0.05 ;$ ns, not significant (Repeated measures [RM] one-way ANOVA). Statistical significances are calculated between $\beta 1-W T$ and mutant cell lines. (C, D) Quantification of the cell area after spreading on FN for 40 min (C) and $4 \mathrm{~h}$ (D) in the presence of $5 \mu \mathrm{M} \mathrm{cilengitide.} \mathrm{Data} \mathrm{are} \mathrm{mean} \pm$ SD of $n>30$ cells. ${ }^{* * *} P<0.001 ;{ }^{* *} P<0.01 ;{ }^{*} P<0.05 ;$ ns, not significant (one-way ANOVA with Kruskal-Wallis test). Statistical significances are calculated between $\beta 1-W T$ and mutant cell lines. (E) Immunostaining of paxillin (red) and F-actin (green) in fibroblasts expressing indicated $\beta 1$ integrin mutants and seeded on FN-coated coverslips for 40 min or $4 \mathrm{~h}$ in the presence of $5 \mu \mathrm{M}$ cilengitide before immunostaining. DAPI was used to stain nuclei. Scale bar, $20 \mu \mathrm{m}$. (F) Quantification of cell surface expression of $\beta 1$ integrin on $\beta 1^{-/-}$ureteric bud cells re-expressing $\beta 1-W T$ integrin or the indicated $\beta 1$ integrin tail mutants measured by flow cytometry. The integrin levels were normalized to the levels on $\beta 1$-WT cells. Data are mean \pm SD. $n=3 .{ }^{* * *} P<0.001$ (RM one-way ANOVA). Statistical significances are calculated between $\beta 1$-WT and mutant cell lines. (G) Quantification of integrin activation after staining total and active $\beta 1$ integrin (9EG7) by flow cytometry. The mean fluorescence intensity ratio of active to total $\beta 1$ integrin was calculated and normalized to the $\beta 1$-WT sample. Data are mean \pm SD. $n=3$. ${ }^{* * *} P<0.001 ;{ }^{* *} P<0.01$ (RM one-way ANOVA). Significances are calculated between $\beta 1$-WT and mutant UB cell lines. (H) Quantification of cell adhesion on Matrigel 30 min after seeding. Data are mean \pm SD. $n=3$. ${ }^{\star * * P<0.001 ~(R M ~ o n e-w a y ~ A N O V A) . ~}$ Statistical significances are calculated between $\beta 1$-WT and mutant UB cell lines.

unspecific band. These findings strongly suggest that the anti$\beta 1$-pTpT antibodies are not specific for $\beta 1-$ pT788/pT789 integrin but rather detect unrelated proteins containing bi-phosphorylated threonine residues, which probably served as major immuneepitope during rabbit immunization. Because none of the studies that used the anti- $\beta 1$-pTpT antibodies controlled the specificity of their results with $\beta 1$ integrin-deficient cells off-target signals may have been misinterpreted.

Western blotting, mass spectrometry and immunostaining failed to detect the phosphorylation of the double threonine motif in 
$\beta 1-T 788 /$ T789 integrin in several cell lines. This observation indicates that the phosphorylation of the double-threonine motif in $\beta 1$ tails is below the detection limit of our assays, or only existent in cell types that have not been analyzed in our study. Our conclusion that the phosphorylation of the double-threonine motif in $\beta 1$-tails is, if at all, a rare event gains support from unbiased high-throughput mass spectrometry data of numerous cell types and experimental conditions. The in silico analysis of these data source revealed that the phosphorylation of $\beta 1-T 788 /$ T789 was not identified so far and two studies reported the phosphorylation of the single threonine-789 in $\beta 1$-tails (Shiromizu et al, 2013; Bian et al, 2014). In contrast, phosphorylation of tyrosine-783 and tyrosine-795 in $\beta 1$ integrin tails has been reported in hundreds of independent studies (phosphosite.org).

Our study also revealed that expression of phospho-mimicking $\beta 1$-TT788/789DD or $\beta 1$-TT788/789EE integrins in $\beta 1$ integrin-null fibroblasts reduced $\beta 1$ integrin activation, integrin-FN binding, adhesion strengthening, and cell spreading, whereas binding strength of single integrins to FN was unaffected by the threonine substitutions. These phenotypes are likely due to the reduced kindlin-2 affinity to $\beta 1$-tails, which was clearly evident in pull-down and MST experiments with $\beta 1-T 788 / 789 D D$ as well as in vitro phosphorylated $\beta 1-$ pT788/pT789 tail polypeptides, irrespective whether talin was present or absent during the measurements. Interestingly, the severity of the cellular phenotypes of wild-type and mutant $\beta 1$ integrin-expressing cells perfectly correlated with the reduced kindlin affinities measured by MST. Whereas the affinity of kindlin-2 for $\beta 1$-TT788/789AA tail peptides was reduced and $\beta 1$-TT788/789AA-expressing fibroblasts showed reduced cell adhesion and spreading, $\beta 1-T T 788 / 789 D D$ substitutions abolished kindlin2 binding and more strongly reduced cell adhesion and spreading.

Our data are in contrast to previous studies which suggested that the phosphorylation of the double-threonine motif through Ndr2 or after PPM1F depletion increases integrin activity (Rehberg et al, 2014; Grimm et al, 2020). Unfortunately, neither of the two studies analyzed the effects of $\beta 1-T 788 / T 789$ phosphorylation in cells expressing phospho-mimicking $\beta 1-T T 788 / 789$ variants. It is also unfortunate that the two studies did not include $\beta 1$ integrindeficient cells to control for the detection of integrin-unrelated protein(s) accidently recognized by the anti- $\beta 1$-pTpT antibodies. We do not challenge that Ndr2 (Rehberg et al, 2014) and PPM1F (Grimm et al, 2020) alter integrin activity. However, we strongly assume, based on our findings, that Ndr2 and PPM1F alter integrin activity by modifying targets other than $\beta 1-T 788 / T 789$.

In conclusion, our findings challenge the existence of a $\beta 1-T 788$ / T789 phosphorylation switch as a major mechanism used by cells to regulate integrin activity and function. However, if such an activity switch would exist, the phosphorylation of the threonine motif in the $\beta 1$-tail would inhibit rather than promote kindlin-2 binding, integrin activity and function.

\section{Materials and Methods}

\section{Antibodies}

The following antibodies or molecular probes were used at indicated concentrations for Western blot (W), immunofluorescence
(IF), or FC: kindlin-2 (MAB2617 from Millipore) W: 1:1,000; talin (8D4 from Sigma-Aldrich) W: 1:1,000; paxillin (610051, clone 349 from BD Transduction Laboratories) IF: 1:500; paxillin (sc-5574 from Santa Cruz Biotechnology) IF: 1:200; integrin $\beta 1$-Alexa 488-conjugated (102211 from BioLegend) FC: 1:300; integrin $\beta 1$ (home-made [Azimifar et al, 2012]) W: 1:10,000, IF: 1:4,000, IP: $2 \mu \mathrm{l} / \mathrm{mg}$ lysate; integrin $\beta 1$ (clone MB1.2 from Millipore) IF: 1:500; integrin $\beta 1$ (clone JB1B from Novus Biologicals) IP: $5 \mu \mathrm{l} / \mathrm{mg}$ lysate; integrin $\alpha 5-P E$ (557446 from Pharmingen) FC: 1:300; IgG2a rat isotype control (13-4321 from eBioscience) FC: 1:300; pT788/789 $\beta 1$ integrin (44-872G from Thermo Fisher Scientific) W: 1:1,000, IF 1:300; pT788/789 $\beta 1$-integrin (ab5189 from Abcam) W: 1:1,000, IF 1:300, phospho-threonine (clone 20H6.1 from Merck) W: 1:1,000, IF 1:500, IP: $5 \mathrm{\mu l} / \mathrm{mg}$ lysate; phospho-threonine (clone RM102 from Thermo Fisher Scientific) W: 1:1,000, IF 1:300, IP: $5 \mu \mathrm{l} / \mathrm{mg}$ lysate; PPM1F (Grimm et al, 2020) W: 1:300; SNX17 (10275-1-AP from Proteintech) W: 1:1,500.

The following secondary antibodies were used: goat anti-rabbit Alexa 488-conjugated (A11008), goat anti-mouse Alexa 488-conjugated (A11029), goat anti-rat Alexa 488-conjugated (A11006), goat anti-mouse Alexa 546-conjugated (A11003) (all from Invitrogen), FACS: 1:500, IF: 1:500; goat anti-rat HRP-conjugated (712035150) (both from Dianova) W: 1:10,000, donkey anti-rabbit Cy3-conjugated (711165-152) (from Jakson ImmunoResearch) IF: 1:500, goat anti-mouse HRP-conjugated (172-1011) and goat anti-rabbit HRP-conjugated (172-1019) (both from Bio-Rad) W: 1:10,000.

Phalloidin-Alexa 647-conjugated (A22287 from Thermo Fisher Scientific) and DAPI (Sigma-Aldrich) were used to stain F-actin and nuclei, respectively.

\section{Synthetic integrin cytosolic peptides}

Synthetic integrin cytosolic peptides were synthesized in house by the Max Planck Institute of Biochemistry Core Facility.

$\beta 1$-WT peptide (HDRREFAKFEKEKMNAKWDTGENPIYKSAVTTVVNPKYEGK-OH), $\beta 1$-scrambled peptide (EYEFEPDKVDTGAKGTKMAKNEKKFRNYTVHNIWESRKVAP-OH), $\beta 1-T T / A A$ peptide (HDRREFAKFEKEKMNAKWDTGENPIYKSAVAAWNPKYEGK-OH), $\beta 1-T T / D D$ peptide (HDRREFAKFEKEKMNAKWDTGENPIYKSAVDDWNPKYEGK-OH), $\beta 1$-рTpT peptide (HDRREFAKFEKEKMNAKWDTGENPIYKSAVPTPTWNPKYEGK-OH), $\beta 1-$ Y783A peptide (HDRREFAKFEKEKMNAKWDTGENPIAKSAVTTWNP-KYEGK-OH), B3/ $\beta 5$-pTpT peptide (KWDTGENPIYKEAVpTpTFTVDFT-FNKFNPKYEGK-OH), and Wwc2-pTpT peptide (LLQEKGGYIPSGPIPT-pTIHENEWKSPSQPG-OH).

\section{Plasmid construction}

Point mutations in the mouse $\beta 1$ integrin tail (TT788/789DD and TT788/789EE) CDNA were introduced by site-directed mutagenesis using the following primers: $\beta 1$-TTDD fwd CCT ATT TAC AAG AGT GCC GTG gat gaT GTG GTC AAT CCG AAG TAT GAG G; $\beta 1$-TTDD rev C CTC ATA CTT CGG ATT GAC CAC AtC atc CAC GGC ACT CTT GTA AAT AGG A; $\beta 1-$ TTEE fwd A AAT CCT ATT TAC AAG AGT GCC GTG gaA gaa GTG GTC AAT CCG AAG TAT GAG G; $\beta 1$-TTEE rev C CTC ATA CTT CGG ATT GAC CAC ttC TtC CAC GGC ACT CTT GTA AAT AGG ATT. For stably expressing the $\beta 1$ integrin CDNAs, the CDNAs were cloned into the retroviral expression vector $p L Z R S$. Retroviral expression constructs of $\beta 1-W T$, $\beta 1-\mathrm{TT788/789AA}, \beta 1-Y 783 \mathrm{~A}$, and $\beta 1$-Y795A have been described 
(Böttcher et al, 2012). The correct sequence of all constructs was confirmed by DNA sequencing (Eurofins Genomics).

\section{Cell lines}

Fibroblasts lacking $\beta 1$ integrin ( $\beta 1-\mathrm{KO}$ ) and reconstituted with $\beta 1$-WT or $\beta 1$-TT788/789AA, $\beta 1-Y 783 A$, and $\beta 1$-Y795A have been described (Böttcher et al, 2012). To generate $\beta 1-T T / D D$ and $\beta 1-T T /$ EE reconstituted cell lines, the $\beta 1-K O$ fibroblasts were retrovirally transduced with cDNAs coding for mouse $\beta 1-T T / D D$ or $\beta 1-T T / E E$ and sorted with the flow cytometer to remove non-infected cells. UB epithelial cells were established from the metanephric kidney anlagen of E11.5 mice carrying floxed $\beta 1$ integrin (Itgb $1^{\text {flox/flox }}$ ) alleles. The T-bud stage UBs were dissected from the metanephric kidney analgen and cultured in 3D-Matrigel in UB culture medium (DMEM/F12 supplemented with 10\% charcoal/dextran treated FCS [Hyclone], $200 \mathrm{nM}$ all-trans- and 9-cis retinoic acid [Sigma-Aldrich] and $15-20 \mathrm{ng} / \mathrm{ml}$ recombinant rat glial cell-derived neurotrophic factor [R\&D Systems]). UB cells were immortalized with SV40 Large-T antigen in the 3D matrix before epithelial UB organoids were dissected and cultured in cell culture dishes in DMEM containing 10\% FBS, $5 \mathrm{ng} / \mathrm{ml}$ glial cell-derived neurotrophic factor. The UB cells were cloned and the floxed alleles were deleted by adenoviral expression of $C r e$ recombinase resulting in $\beta 1$ integrin knockout cells ( $\beta 1-K O)$, and reconstituted with either $\beta 1-W T, \beta 1-T T / A A, \beta 1-T T / D D, \beta 1-T T / E E$, $\beta 1-Y 783 A$, or $\beta 1$-Y795A. A172 sg-control and A172 PPM1F KO cells have been described (Grimm et al, 2020). All cell lines were cultured in DMEM supplemented with $10 \%$ FCS and Penicillin/Streptomycin.

\section{Transient and stable transfection/transduction}

To generate stable cell lines, VSV-G pseudotyped retroviral vectors were produced by transient transfection of 293T (human embryonic kidney) cells. Viral particles were concentrated from cell culture supernatant (Pfeifer et al, 2000) and used for infections. Cells were transiently transfected with Lipofectamine 2000 (Invitrogen) according to the manufacturer's protocol.

\section{FC}

FC was carried out with a LSRFortessa Flow Cytometer (BD Biosciences) equipped with FACS DiVa software (BD Biosciences). Cells were detached with trypsin/EDTA, sedimented by centrifugation (290g for $5 \mathrm{~min}$ ) and suspended in PBS (P4417; Sigma-Aldrich) containing 1\% BSA. 2-4 × $10^{5}$ cells were incubated with primary antibodies for $1 \mathrm{~h}$ on ice, washed with cold PBS supplemented with $1 \%$ BSA before incubation with the secondary antibody for $45 \mathrm{~min}$ on ice in the dark. Data analysis was carried out with Flowjo (version 9.4.10; BD Biosciences).

\section{Integrin peptide ELISA}

Synthetic integrin cytosolic peptides ( $\beta 1-W T, \beta 1-T T / A A, \beta 1-T T / D D$, $\beta 1$-pTpT, $\beta 3 / \beta 5$-рTpT, and Wwc2-pTpT) were dissolved in PBS to a concentration of $500 \mathrm{nM}$ and $100 \mu \mathrm{l}$ was immobilized on 96-well MaxiSorp plates (Nalge Nunc) overnight at $4^{\circ} \mathrm{C}$. The plates were blocked with $200 \mu \mathrm{l}$ PBS containing 3\% BSA for $1 \mathrm{~h}$ at room temperature and then washed thrice with $200 \mu \mathrm{l}$ PBS. Different dilutions of the anti- $\beta 1$-pTpT antibodies (Thermo Fisher Scientific and Abcam) in $100 \mu \mathrm{l}$ PBS supplemented with $3 \%$ BSA were incubated for $2 \mathrm{~h}$ at room temperature. After washing thrice with $200 \mu \mathrm{l}$ PBS, $100 \mu \mathrm{l}$ of anti-rabbit-IgG HRP-conjugate was added (1:10,000 in PBS supplemented with 3\% BS) and incubated for $1 \mathrm{~h}$ at room temperature. The plates were washed thrice with $200 \mu \mathrm{l} \mathrm{PBS}$, developed with $100 \mu$ l of ABTS substrate solution (1-Step ABTS; Thermo Fisher Scientific) before measuring absorbance at $\lambda=405 \mathrm{~nm}$ in a SpectraMax ABS Plus plate reader (Molecular Devices).

\section{Peptide pull-down assays}

Pull-down assays were performed with $\mathrm{N}$-terminally desthio biotinylated $\beta 1-W T, \beta 1-S c r, \beta 1-T T / A A, \beta 1-T T / D D, \beta 1-p T p T$ peptides. Before use, peptides were immobilized on $25 \mu$ l Dynabeads MyOne Streptavidin C1 (10 mg/ml; Invitrogen) in Mammalian Protein Extraction Reagent (Thermo Fisher Scientific) containing protease inhibitors (cOmplete; Roche) and phosphatase inhibitors (Phosphatase Inhibitor Cocktail 2 and 3; Sigma-Aldrich) for $3 \mathrm{~h}$ at $4^{\circ} \mathrm{C}$. Cell lysates were prepared with MPER containing protease and phosphatase inhibitors and $0.5 \mathrm{mg}$ of supernatant was incubated with the peptide-coated beads at $4^{\circ} \mathrm{C}$ under constant rotation. For pull-downs with recombinant proteins, synthetic $\beta 1$ integrin tail peptides were immobilized on $25 \mu \mathrm{l}$ Dynabeads MyOne Streptavidin C1 $(10 \mathrm{mg} / \mathrm{ml}$; Invitrogen) for $3 \mathrm{~h}$ at $4^{\circ} \mathrm{C}$, incubated with $2 \%$ BSA in Mammalian Protein Extraction Reagent (Thermo Scientific Scientific) for 30 min at $4^{\circ} \mathrm{C}$ to block unspecific binding before adding kindlin-2 or THD (conc 2.5 and $8.5 \mathrm{nM}$, respectively) and further incubation on a rotator for $2 \mathrm{~h}$ at $4^{\circ} \mathrm{C}$. After washing the beads three times with lysis buffer, the proteins bound to the beads were eluted using Laemmli buffer, separated on a $10 \%$ SDS-PAGE, and analyzed by Western blotting.

\section{MST}

All MST measurements were performed on a Monolith NT.115 redblue (Nanotemper) using premium-coated capillaries to reduce non-specific interaction of the proteins with the glass surface. Both interaction partners (ligand and receptor) were transferred into MST buffer (20 mM Tris, pH 7.5, 200 mM sodium chloride, 1 mM tris(2carboxyethyl)phosphine [TCEP], 0.05\% Tween-20) to avoid artifacts derived from buffer mismatches. $200 \mathrm{nM}$ Atto488-labeled integrin $\beta 1$ WT tails synthesized in house by the Max Planck Institute of Biochemistry Core Facility were used as ligands. The measurements were carried out at 20\% light emitting diode power and $20 \%$ and $40 \%$ MST power. Data were analyzed using the MO Affinity Analysis Software (Nanotemper).

\section{$\beta 1$ integrin immunoprecipitations}

For immunoprecipitation (IP) of $\beta 1$ integrin, cells were lysed in $\beta 1$ lysis buffer (50 mM Tris- $\mathrm{HCl}$, pH 8.0, $150 \mathrm{mM} \mathrm{NaCl}, 1 \%$ Triton X-100, $0.05 \%$ sodium deoxycholate [SDC], $10 \mathrm{mM}$ EDTA-containing protease inhibitors [cOmplete; Roche], phosphatase inhibitors [Phosphatase Inhibitor Cocktail 2 and 3; Sigma-Aldrich], and $10 \mathrm{mM}$ phosphatase saturating substrate [para-nitrophenolphosphate [pNPP]; SigmaAldrich]) and incubated with rabbit anti- $\beta 1$ integrin ectodomain 
antibodies $(2 \mu \mathrm{l} / \mathrm{mg}$ cell lysate home-made to IP total [active and inactive] mouse $\beta 1$ integrin; $5 \mu \mathrm{g} / \mathrm{mg}$ cell lysate JB1B to IP human $\beta 1$ integrin) for $2 \mathrm{~h}$ at $4^{\circ} \mathrm{C}$ while rotating. Subsequently, lysates were incubated with $50 \mu \mathrm{l}$ washed protein A/G Plus Agarose (Santa Cruz Biotechnology) for $2 \mathrm{~h}$ at $4^{\circ} \mathrm{C}$. After repeated washing steps with lysis buffer, proteins were eluted from the beads using Laemmli buffer, separated on a $8 \%$ SDS-PAGE and analyzed by Western blotting.

\section{Atomic force microscopy-based single-cell force spectroscopy}

For cell attachment, tip-less $\mathrm{V}$-shaped silicon nitride tip-less cantilevers (NP-O; Bruker) were plasma cleaned (PDC-32G; Harrick Plasma) and then incubated with $2 \mathrm{mg} / \mathrm{ml}$ concanavalin $A$ (Sigma-Aldrich) in PBS at $4^{\circ} \mathrm{C}$ overnight. For substrate coatings, a 200- $\mu$ m-thick four-segmented polydimethylsilane (PDMS) mask fused to the surface of glass bottom Petri dishes (World Precision Instruments) was used (Yu et al, 2015). Each of the four PDMS framed glass surfaces were incubated with $50 \mu \mathrm{g} / \mathrm{ml}$ FNIII7-10 ${ }^{\mathrm{RGD}}$ or FNIII7$10^{\triangle \mathrm{RGD}}$ in PBS at $4^{\circ} \mathrm{C}$ overnight. For SCFS, a Nanowizard II AFM equipped with a CellHesion module (both JPK Instruments) was mounted onto an inverted microscope (Observer Z1; Zeiss). The temperature of the medium in the Petri dish was maintained at $37^{\circ} \mathrm{C}$ (PetriDish heater; JPK Instruments). 200- $\mu$ m-long cantilevers having nominal spring constants of $0.06 \mathrm{~N} / \mathrm{m}$ were used. Each cantilever was calibrated prior the measurement by determining its sensitivity and spring constant using the thermal noise analysis using inbuild routines. To adhere a single fibroblast to the AFM cantilever, overnight serum-starved fibroblasts with confluency up to $~ 80 \%$ were washed with PBS, trypsin/EDTA-detached for 2 min, suspended in SCFS media (DMEM supplemented with $20 \mathrm{mM}$ Hepes) containing 1\% (vol/vol) FCS, pelleted, and resuspended in serum free SCFS media. Fibroblasts were allowed to recover for at least 30 min from trypsin treatment (Schubert et al, 2014). Fibroblasts in suspension were incubated with $1 \mu \mathrm{M}$ cilengitide (Sigma-Aldrich) for 30 min before and throughout the experiments. To attach a single fibroblast to the apex of the cantilever, the fibroblast suspension was pipetted onto the functionalized Petri dishes, the concanavalin A-coated cantilever was lowered onto a single fibroblast at $10 \mu \mathrm{m} / \mathrm{s}$ until a force of $5 \mathrm{nN}$ was recorded and was subsequently retracted after $5 \mathrm{~s}$ contact at $10 \mu \mathrm{m} / \mathrm{s}$ for $100 \mu \mathrm{m}$. The cantilever-bound fibroblast was incubated for 10-15 min for binding probability experiments and $\sim 5 \mathrm{~min}$ for adhesion force measurements. Using differential interference contract (DIC) microscopy, the morphological state of the fibroblast was monitored. For binding probability experiments, the cantilever-bound fibroblast was lowered onto the substrate at $1 \mu \mathrm{m} / \mathrm{s}$ until a contact force of $200 \mathrm{pN}$ was reached and the cantilever was retracted after $250 \mathrm{~ms}$ at constant hight at $1 \mu \mathrm{m} / \mathrm{s}$ for $\geq 13 \mu \mathrm{m}$ until the fibroblast and substrate were fully separated. This resulted in a total contact time between fibroblasts and substrate of $\sim 300 \mathrm{~ms}$. This experimental cycle was repeated for 100 times for each fibroblast, whereby the fibroblast was allowed to recover for $0.5 \mathrm{~s}$ between cycles and the contact area on the substrate was altered. FD curves were analyzed for unbinding events using in-build JPK software to determine binding probability as the ratio of FD curves showing unbinding events and total number of attempts. For adhesion force experiments, the rounded cantilever-bound fibroblast was lowered onto the substrate at $5 \mu \mathrm{m} / \mathrm{s}$ until a contact force of $1 \mathrm{nN}$ was recorded. For contact times of 5, 20,50, or $120 \mathrm{~s}$, the cantilever was maintained at constant height and subsequently retracted at $5 \mu \mathrm{m} / \mathrm{s}$ for $100 \mu \mathrm{m}$ until the fibroblast and substrate were fully separated. After the experimental cycle, the fibroblast was allowed to recover for a time period equal to contact time before measuring the adhesion force for a different contact time. A single fibroblast was used to probe the adhesion force for all contact times or until morphological changes, that is, spreading, was observed. The sequence of contact time measurements and area of the substrate were varied. Adhesion forces were determined after baseline correction of FD curves with JPK software (JPK Instruments).

\section{Integrin activation assay}

Cells were trypsinized, split into two fractions, and placed on ice. The cell fractions were stained for the 9EG7 epitope, reporting activated $\beta 1$ integrin or total $\beta 1$ integrin for $1 \mathrm{~h}$ on ice in PBS supplemented with $1 \%$ BSA. Cells were washed thrice with PBS and incubated with Alexa 488-conjugated secondary antibody in PBS supplemented with $1 \%$ BSA for 45 min on ice in the dark. Cells were washed and fluorescence intensity was measured by FC (BD LSRII, FACSDivaTM software; BD Biosciences).

For ELISA, starved cells were trypsinized and kept in suspension in DMEM supplemented with $3 \%$ BSA for $45 \mathrm{~min}$ at $37^{\circ} \mathrm{C}$ before seeding 40,000 cells into $\mathrm{FN}$-coated $(10 \mu \mathrm{g} / \mathrm{ml})$ flat-bottom 96 well plates. After adhering for $40 \mathrm{~min}$ at $37^{\circ} \mathrm{C}$, the cells were fixed with $2 \%$ PFA and washed with PBS. Afterwards, cells were blocked with PBS containing 3\% BSA for 60 min at room temperature and stained for the $9 \mathrm{EG} 7$ epitope of $\beta 1$ integrin or total integrin $\beta 1$ (Millipore) overnight in PBS containing 3\% BSA at $4^{\circ} \mathrm{C}$. After three washes with PBS, the cells were incubated with the secondary HRP-conjugated goat anti-rat IgG antibody in PBS containing $3 \%$ BSA for $1 \mathrm{~h}$ at RT. Finally, cells were intensively washed, $100 \mu \mathrm{l}$ of ABTS substrate solution (1-Step ABTS; Thermo Fisher Scientific) was added and the absorption was measured at $\lambda=405 \mathrm{~nm}$ in a SpectraMax ABS Plus plate reader (Molecular Devices).

\section{Spreading and adhesion assays}

Cells were grown to $70 \%$ confluence followed by overnight incubation in DMEM containing $0.2 \%$ FCS. After detaching with trypsin/EDTA, cells were serum starved for $1 \mathrm{~h}$ at $37^{\circ} \mathrm{C}$ in adhesion assay medium (10 mM Hepes, pH 7.4; $137 \mathrm{mM} \mathrm{NaCl} ; 1 \mathrm{mM}$ $\mathrm{MgCl}_{2} ; 1 \mathrm{mM} \mathrm{CaCl} ; 2.7 \mathrm{mM} \mathrm{KCl} ; 4.5 \mathrm{~g}$ /liter Glucose; and 3\% BSA [wt/vol]) or DMEM containing 3\% BSA in the presence or absence of $5 \mu \mathrm{M}$ cilengitide.

For adhesion assays, flat-bottom 96-well plates were coated with $10 \mu \mathrm{g} / \mathrm{ml}$ FN (Calbiochem) or 1:500 dilution of Matrigel (Corning) and blocked with PBS containing 3\% BSA. Cells were then plated $(40,000$ per well) in adhesion buffer or DMEM containing 3\% BSA $\pm 5 \mu \mathrm{M}$ cilengitide and incubated for 15 or $40 \mathrm{~min}$ at $37^{\circ} \mathrm{C}$. After vigorous washing with PBS to remove nonadherent cells, cells were fixed with PBS containing 4\% PFA and adherent cells measured by staining with crystal violet ( $0.1 \%$ in $20 \%$ methanol) for $15 \mathrm{~min}$. After extensive washing with $\mathrm{H}_{2} \mathrm{O}$, the color was released by $2 \% \mathrm{SDS} / \mathrm{H}_{2} \mathrm{O}$ 
and the absorption was measured at $\lambda=570 \mathrm{~nm}$ in a SpectraMax ABS Plus plate reader (Molecular Devices).

For cell spreading, 40,000 cells were seeded on $10 \mu \mathrm{g} / \mathrm{ml} \mathrm{FN-}$ coated coverslips, cultured in DMEM containing 3\% BSA $\pm 5 \mu \mathrm{M}$ cilengitide at $37^{\circ} \mathrm{C}$, fixed with $4 \%$ PFA (wt/vol) in PBS, and stained with phalloidin-Alexa 488 and DAPI. At least 10 images were taken using a Zeiss LSM 780 confocal laser scanning microscope equipped with 40×/NA 1.4 oil objective and cell spreading area was measured using ImageJ (release 1.53 [Schneider et al, 2012]).

\section{Mass spectrometry analysis}

To identify proteins immunoprecipitated with anti- $\beta 1$-pTpT antibodies, cells were lysed in $\beta 1$ lysis buffer ( $50 \mathrm{mM}$ Tris- $\mathrm{HCl}, \mathrm{pH}$ 8.0, $150 \mathrm{mM} \mathrm{NaCl}, 1 \%$ Triton X-100, 0.05\% SDC, 10 mM EDTA containing protease inhibitors [cOmplete; Roche], and phosphatase inhibitors [Phosphatase Inhibitor Cocktail 2 and 3; Sigma-Aldrich]) and incubated with rabbit anti- $\beta 1$-pTpT antibodies (Thermo Fisher Scientific) for overnight at $4^{\circ} \mathrm{C}$ while rotating. Subsequently, lysates were incubated with $50 \mu \mathrm{l}$ washed protein A/G Plus Agarose (Santa Cruz Biotechnology) for $2 \mathrm{~h}$ at $4^{\circ} \mathrm{C}$. For reduction and alkylation of the proteins, previously PBS-washed beads were incubated with SDC buffer containing 1\% SDC (Sigma-Aldrich), 40 mM 2-chloroacetamide (Sigma-Aldrich), 10 mM TCEP (Thermo Fisher Scientific), and $100 \mathrm{mM}$ Tris, $\mathrm{pH} 8.0$, at $37^{\circ} \mathrm{C}$. After incubation for $20 \mathrm{~min}$ at $37^{\circ} \mathrm{C}$, the samples were diluted 1:2 with MS-grade water (VWR). Proteins were digested overnight at $37^{\circ} \mathrm{C}$ with $0.5 \mu \mathrm{g}$ trypsin (Promega). Then, the beads material was centrifuged and the supernatant was collected. In addition, the beads were washed with $100 \mu \mathrm{l}$ of buffer $\mathrm{A}$ ( $0.1 \%$ formic acid), followed by centrifugation and collection of the supernatant. The combined supernatants were acidified with TFA (Merck) to a final concentration of $1 \%$. Precipitated SDC was removed by centrifugation and the peptide mixture was desalted via SCX StageTips (Rappsilber et al, 2007). Samples were vacuum-dried and re-suspended in $10 \mu \mathrm{l}$ of buffer $\mathrm{A}$.

To identify phosphorylated $\beta 1$ integrin, $\beta 1$ integrins were immunoprecipitated from $\beta 1-W T$ fibroblasts kept in suspension, seeded for 45 and 90 min on FN or arrested in mitosis as indicated before. Proteins were eluted from the beads using Laemmli buffer, separated on a $8 \%$ SDS-PAGE proteins and stained with Coomassie. Gel lanes of interest were excised, chopped, and washed two times with $150 \mu \mathrm{l}$ of destaining buffer ( $25 \mathrm{mM}$ ammonium bicarbonate, $50 \%$ ethanol). Gel pieces were dehydrated two times in $150 \mu \mathrm{l}$ of $100 \%$ ethanol and the gel pieces were dried by vacuum centrifugation. Then, $50 \mu \mathrm{l}$ of digestion buffer ( $25 \mathrm{mM}$ Tris- $\mathrm{HCl}, 10 \%$ acetonitrile, and $10 \mathrm{ng} / \mu \mathrm{l}$ of trypsin) was added. After incubation for 20 min on ice, $50 \mu \mathrm{l}$ of ammonium bicarbonate buffer $(25 \mathrm{mM})$ was added and the gel pieces were incubated at $37^{\circ} \mathrm{C}$ overnight. Peptides in the supernatant were collected and more peptides were extracted from the gel pieces by repeated incubation of the gel pieces at $25^{\circ} \mathrm{C}$ in $100 \mu \mathrm{l}$ of extraction buffer (3\% TFA and 30\% acteonitrile), subsequent centrifugation and collection of the supernatants. Finally, the gel pieces were dehydrated by incubation at $25^{\circ} \mathrm{C}$ in $100 \mu \mathrm{l}$ of $100 \%$ acetonitrile and the supernatant was unified with the supernatants from previous extraction steps. Acetonitrile was removed by vacuum-centrifugation and $70 \mu \mathrm{l}$ of $2 \mathrm{M}$ Tris- $\mathrm{HCl}$ as well as $10 \mathrm{mM}$ TCEP and $40 \mathrm{mM}$ 2-chloroacetamide was added. After incubation for 30 min at $37^{\circ} \mathrm{C}$, peptides were acidified to $1 \%$ TFA and desalted using StageTips.

\section{LC MS/MS data acquisition}

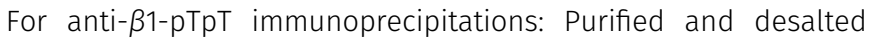
peptides were loaded onto a 30-cm column (inner diameter: 75 microns; packed in-house with ReproSil-Pur C18-AQ 1.9-micron beads; Dr. Maisch $\mathrm{GmbH}$ ) via the autosampler of the Thermo EasynLC 1000 (Thermo Fisher Scientific). Peptides were loaded in buffer A $(0.1 \%$ formic acid $)$ at $400 \mathrm{nl} / \mathrm{min}$ and percentage of buffer $\mathrm{B}(80 \%$ acetonitrile, $0.1 \%$ formic acid) was ramped from $8 \%$ to $30 \%$ over $35 \mathrm{~min}$ followed by a ramp to $35 \%$ over $10 \mathrm{~min}$ and then $58 \%$ over the next 5 min, 95\% over the next 5 min, and maintained at 95\% for another 5 min.

Data acquisition on the timsTOF Pro (Brucker) was performed using timsControl. The mass spectrometer was operated in datadependent PASEF mode with one survey thermal ionization mass spectrometry (TIMS)-MS and 10 PASEF MS/MS scans per acquisition cycle. Analysis was performed in a mass scan range from 100 to 1700 $\mathrm{m} / \mathrm{z}$ and an ion mobility range from $1 / \mathrm{KO}=1.35$ to $0.85 \mathrm{Vs} \mathrm{cm}^{-2}$ using equal ion accumulation and ramp time in the dual TIMS analyzer of $100 \mathrm{~ms}$ each at a spectra rate of $9.43 \mathrm{~Hz}$. Suitable precursor ions for MS/MS analysis were isolated in a window of 2 Th for $\mathrm{m} / \mathrm{z}<700$ and 3 Th for $\mathrm{m} / \mathrm{z}>700$ by rapidly switching the quadrupole position in sync with the elution of precursors from the TIMS device. The collision energy was lowered as a function of ion mobility, starting from $45 \mathrm{eV}$ for $1 / \mathrm{KO}=1.3 \mathrm{Vs} \mathrm{cm}^{-2}$ to $27 \mathrm{eV}$ for $0.85 \mathrm{Vs} \mathrm{cm}^{-2}$. Singly charged precursor ions were excluded with a polygon filter mask and further $\mathrm{m} / \mathrm{z}$ and ion mobility information was used for " $\mathrm{dy}$ namic exclusion" to avoid re-sequencing of precursors that reached a "target value" of 14,500 a.u. The ion mobility dimension was calibrated linearly using three ions from the Agilent ESI LC/MS tuning mix (m/z, 1/K0: 622.0289, $0.9848 \mathrm{Vs} \mathrm{cm}^{-2} ; 922.0097 \mathrm{Vs} \mathrm{cm}{ }^{-2}$, $1.1895 \mathrm{Vs} \mathrm{cm}^{-2}$; $1221.9906 \mathrm{Vs} \mathrm{cm}^{-2}$, and $1.3820 \mathrm{Vs} \mathrm{cm}^{-2}$ ).

To detect phosphorylated $\beta 1$ integrin: Purified and desalted peptides were loaded onto a 30-cm column (inner diameter: 75 microns; packed in-house with Reprosil-Pur C18-AQ 1.9-micron beads; Dr. Maisch $\mathrm{GmbH}$ ) via the autosampler of the Thermo Easy$\mathrm{nLC} 1000$ (Thermo Fisher Scientific) at $60^{\circ} \mathrm{C}$. Using the nanoelectrospray interface, eluting peptides were directly sprayed onto the benchtop Orbitrap mass spectrometer Q Exactive HF (Thermo Fisher Scientific).

Peptides were loaded in buffer A ( $0.1 \%$ formic acid) at $250 \mathrm{nl} / \mathrm{min}$ and percentage of buffer B ( $80 \%$ acetonitrile, $0.1 \%$ formic acid) increased to $30 \%$ over 45 min followed by an increase to $60 \%$ over 5 min then $95 \%$ over the next 5 min. Percentage of buffer B was maintained at $95 \%$ for another $5 \mathrm{~min}$. The mass spectrometer was operated in a data-dependent mode with survey scans from 300 to $1,650 \mathrm{~m} / \mathrm{z}$ (resolution of 60,000 at $\mathrm{m} / \mathrm{z}=200$ ), and up to 10 of the top precursors were selected and fragmented using higher energy collisional dissociation (HCD with a normalized collision energy of value of 28). The MS2 spectra were recorded at a resolution of 30,000 (at $\mathrm{m} / \mathrm{z}=200$ ). Automatic gain control target for MS and MS2 scans were set to $3 \times 10^{6}$ and $1 \times 10^{5}$, respectively, within a maximum injection time of 100 and 60 ms for MS and MS2 scans, respectively. Dynamic exclusion was set to $30 \mathrm{~ms}$. 


\section{LC MS/MS data analysis}

Raw data were processed using the MaxQuant computational platform (version 1.6.17.0) (Cox \& Mann, 2008) with standard settings applied for ion mobility data (Prianichnikov et al, 2020). Shortly, the peak list was searched against the Uniprot database of Mus musculus (55,466 entries) with an allowed precursor mass deviation of 10 ppm and an allowed fragment mass deviation of 20 ppm. To detect integrin phosphopeptides, we allowed precursor mass deviation of $4.5 \mathrm{ppm}$ and an allowed fragment mass deviation of $20 \mathrm{ppm}$.

MaxQuant by default enables individual peptide mass tolerances, which was used in the search. Cysteine carbamidomethylation was set as static modification, and methionine oxidation, phosphorylation (on $\mathrm{S}, \mathrm{T}$, and $\mathrm{Y}$ ), and $\mathrm{N}$-terminal acetylation as variable modifications. The match between the run feature was enabled, and proteins were quantified across samples using the label-free quantification algorithm in MaxQuant as label-free quantification intensities.

\section{Statistical analysis}

All experiments were repeated at least three times (as indicated in figure legends). Most statistical significances ( ${ }^{*} P<0.05$; ${ }^{* *} P<0.01$; ${ }^{* * *} P<0.001 ;{ }^{* * * *} P<0.0001$, ns, not significant) were determined by one-way ANOVA. Two-tailed Mann-Whitney $U$ tests were applied to determine significant differences between adhesion forces or the binding probability of fibroblast lines at different conditions, $P$-values comparing adhesion strengthening differences were calculated by two-tailed extra sum of squares F-test and $P$-values comparing rupture force difference were calculated using KruskalWallis test. The statistical analysis was performed using Prism (version 9.00; GraphPad Software) in-build routines.

\section{Supplementary Information}

Supplementary Information is available at https://doi.org/10.26508/lsa. 202101301.

\section{Acknowledgements}

We thank Hildegard Reiter for expert technical help. We thank Dr. Christof Hauck for providing the A172 Control and PPM1F KO cells. The work was supported by the Deutsche Forschungsgemeinschaft (SFB914, project A05 to RT Böttcher), the Swiss National Science Foundation (grant no. 31003A_182587/1), the European Research Council (Polnt, Proposal ID 810104 to R Fässler) and the Max-Planck Society (to R Fässler).

\section{Author Contributions}

RT Böttcher: conceptualization, data curation, formal analysis, funding acquisition, validation, investigation, visualization, methodology, and writing-original draft, review, and editing.

N Strohmeyer: data curation, formal analysis, validation, investigation, visualization, methodology, and writing-original draft, review, and editing.
J Aretz: investigation, methodology, and writing-review and editing. R Faessler: conceptualization, resources, supervision, funding acquisition, project administration, and writing-original draft, review, and editing.

\section{Conflict of Interest Statement}

The authors declare that they have no conflict of interest.

\section{References}

Anthis NJ, Haling JR, Oxley CL, Memo M, Wegener KL, Lim CJ, Ginsberg MH, Campbell ID (2009) Beta integrin tyrosine phosphorylation is a conserved mechanism for regulating talin-induced integrin activation. J Biol Chem 284: 36700-36710. doi:10.1074/jbc.M109.061275

Azimifar SB, Böttcher RT, Zanivan S, Grashoff C, Krüger M, Legate KR, Mann M, Fässler R (2012) Induction of membrane circular dorsal ruffles requires co-signalling of integrin-ilk-complex and egf receptor. I Cell Sci 125: 435-448. doi:10.1242/jcs.091652

Benito-Jardón M, Strohmeyer N, Ortega-Sanchís S, Bharadwaj M, Moser M, Müller DJ, Fässler R, Costell M (2020) av-Class integrin binding to fibronectin is solely mediated by RGD and unaffected by an RGE mutation. I Cell Biol 219: e202004198. doi:10.1083/jcb.202004198

Bhalla S, Shiratsuchi H, Craig DH, Basson MD (2009) Beta(1)-integrin mediates pressure-stimulated phagocytosis. Am J Surg 198: 611-616. doi:10.1016/j.amjsurg.2009.07.006

Bharadwaj M, Strohmeyer N, Colo GP, Helenius J, Beerenwinkel N, Schiller HB, Fässler R, Müller DJ (2017) $\alpha$ V-class integrins exert dual roles on $\alpha 5 \beta 1$ integrins to strengthen adhesion to fibronectin. Nat Commun 8: 14348. doi:10.1038/ncomms14348

Bian Y, Song C, Cheng K, Dong M, Wang F, Huang J, Sun D, Wang L, Ye M, Zou H (2014) An enzyme assisted rp-rplc approach for in-depth analysis of human liver phosphoproteome. J Proteomics 96: 253-262. doi:10.1016/ j.jprot.2013.11.014

Böttcher RT, Stremmel C, Meves A, Meyer H, Widmaier M, Tseng HY, Fässler R (2012) Sorting nexin 17 prevents lysosomal degradation of $\beta 1$ integrins by binding to the $\beta 1$-integrin tail. Nat Cell Biol 14: 584-592. doi:10.1038/ ncb2501

Böttcher RT, Veelders M, Rombaut P, Faix J, Theodosiou M, Stradal TE, Rottner K, Zent R, Herzog F, Fässler R (2017) Kindlin-2 recruits paxillin and arp2/3 to promote membrane protrusions during initial cell spreading. I Cell Biol 216: 3785-3798. doi:10.1083/jcb.201701176

Chatterjee D, D'Souza A, Zhang Y, Bin W, Tan SM, Bhattacharjya S (2018) Interaction analyses of 14-3-3ろ, Dok1, and phosphorylated integrin $\beta$ cytoplasmic tails reveal a bi-molecular switch in integrin regulation. J Mol Biol 430: 4419-4430. doi:10.1016/j.jmb.2018.09.008

Chen H, Zou Z, Sarratt KL, Zhou D, Zhang M, Sebzda E, Hammer DA, Kahn ML (2006) In vivo beta1 integrin function requires phosphorylationindependent regulation by cytoplasmic tyrosines. Genes Dev 20: 927-932. doi:10.1101/gad.1408306

Cluzel C, Saltel F, Lussi J, Paulhe F, Imhof BA, Wehrle-Haller B (2005) The mechanisms and dynamics of (alpha) $v($ beta) 3 integrin clustering in living cells. J Cell Biol 171: 383-392. doi:10.1083/jcb.200503017

Cox J, Mann M (2008) Maxquant enables high peptide identification rates, individualized p.P.B.-range mass accuracies and proteome-wide protein quantification. Nat Biotechnol 26: 1367-1372. doi:10.1038/ nbt.1511

Craig DH, Gayer CP, Schaubert KL, Wei Y, Li J, Laouar Y, Basson MD (2009) Increased extracellular pressure enhances cancer cell integrinbinding affinity through phosphorylation of beta1-integrin at 
threonine 788/789. Am J Physiol Cell Physiol 296: C193-C204 doi:10.1152/ajpcell.00355.2008

Czuchra A, Meyer H, Legate KR, Brakebusch C, Fässler R (2006) Genetic analysis of beta1 integrin "activation motifs" in mice. J Cell Biol 174: 889-899. doi:10.1083/jcb.200604060

Fagerholm S, Morrice N, Gahmberg CG, Cohen P (2002) Phosphorylation of the cytoplasmic domain of the integrin cd18 chain by protein kinase $\mathrm{C}$ isoforms in leukocytes. J Biol Chem 277: 1728-1738. doi:10.1074/ jbc.M106856200

Fagerholm SC, Hilden TJ, Nurmi SM, Gahmberg CG (2005) Specific integrin alpha and beta chain phosphorylations regulate Ifa-1 activation through affinity-dependent and -independent mechanisms. J Cell Biol 171: 705-715. doi:10.1083/jcb.200504016

Gahmberg CG, Grönholm M, Madhavan S, Jahan F, Mikkola E, Viazmina L, Koivunen E (2019) Regulation of cell adhesion: A collaborative effort of integrins, their ligands, cytoplasmic actors, and phosphorylation. Q Rev Biophys 52: e10. doi:10.1017/S0033583519000088

García-Alvarez B, de Pereda JM, Calderwood DA, Ulmer TS, Critchley D, Campbell ID, Ginsberg MH, Liddington RC (2003) Structural determinants of integrin recognition by talin. Mol Cell 11: 49-58. doi:10.1016/s1097-2765(02)00823-7

Gingras AR, Ziegler WH, Bobkov AA, Joyce MG, Fasci D, Himmel M, Rothemund S, Ritter A, Grossmann JG, Patel B, et al (2009) Structural determinants of integrin binding to the talin rod. J Biol Chem 284: 8866-8876. doi:10.1074/jbc.M805937200

Grimm TM, Dierdorf NI, Betz K, Paone C, Hauck CR (2020) Ppm1f controls integrin activity via a conserved phospho-switch. J Cell Biol 219: e202001057. doi:10.1083/jcb.202001057

Han J, Lim CJ, Watanabe N, Soriani A, Ratnikov B, Calderwood DA, PuzonMcLaughlin W, Lafuente EM, Boussiotis VA, Shattil SJ, et al (2006) Reconstructing and deconstructing agonist-induced activation of integrin alphaiibbeta3. Curr Biol 16: 1796-1806. doi:10.1016/ j.cub.2006.08.035

Hilden TJ, Valmu L, Kärkkäinen S, Gahmberg CG (2003) Threonine phosphorylation sites in the beta 2 and beta 7 leukocyte integrin polypeptides. J Immunol 170: 4170-4177. doi:10.4049/ jimmunol.170.8.4170

Hirst R, Horwitz A, Buck C, Rohrschneider L (1986) Phosphorylation of the fibronectin receptor complex in cells transformed by oncogenes that encode tyrosine kinases. Proc Natl Acad Sci U S A 83: 6470-6474. doi:10.1073/pnas.83.17.6470

Höffken V, Hermann A, Pavenstädt H, Kremerskothen J (2021) Wwc proteins: Important regulators of hippo signaling in cancer. Cancers (Basel) 13: 306. doi:10.3390/cancers13020306

Hynes RO (2002) Integrins: Bidirectional, allosteric signaling machines. Cell 110: 673-687. doi:10.1016/s0092-8674(02)00971-6

Johansson MW, Larsson E, Lüning B, Pasquale EB, Ruoslahti E (1994) Altered localization and cytoplasmic domain-binding properties of tyrosinephosphorylated beta 1 integrin. J Cell Biol 126: 1299-1309. doi:10.1083/ jcb.126.5.1299

Kiema T, Lad Y, Jiang P, Oxley CL, Baldassarre M, Wegener KL, Campbell ID, Ylänne J, Calderwood DA (2006) The molecular basis of filamin binding to integrins and competition with talin. Mol Cell 21: 337-347. doi:10.1016/j.molcel.2006.01.011

Kim SM, Kwon MS, Park CS, Choi KR, Chun JS, Ahn J, Song WK (2004) Modulation of thr phosphorylation of integrin beta1 during muscle differentiation. J Biol Chem 279: 7082-7090. doi:10.1074/ jbc.M311581200

Liu J, Wang Y, Goh WI, Goh H, Baird MA, Ruehland S, Teo S, Bate N, Critchley DR, Davidson MW, et al (2015) Talin determines the nanoscale architecture of focal adhesions. Proc Natl Acad Sci U S A 112: E4864-E4873. doi:10.1073/pnas.1512025112
Meves A, Geiger T, Zanivan S, DiGiovanni J, Mann M, Fässler R (2011) Beta1 integrin cytoplasmic tyrosines promote skin tumorigenesis independent of their phosphorylation. Proc Natl Acad Sci U S A 108: 15213-15218. doi:10.1073/pnas.1105689108

Moser M, Nieswandt B, Ussar S, Pozgajova M, Fässler R (2008) Kindlin-3 is essential for integrin activation and platelet aggregation. Nat Med 14: 325-330. doi:10.1038/nm1722

Nurmi SM, Gahmberg CG, Fagerholm SC (2006) 14-3-3 proteins bind both filamin and alphalbeta2 integrin in activated t cells. Ann N Y Acad Sci 1090: 318-325. doi:10.1196/annals.1378.035

Pfeifer A, Kessler T, Silletti S, Cheresh DA, Verma IM (2000) Suppression of angiogenesis by lentiviral delivery of pex, a noncatalytic fragment of matrix metalloproteinase 2. Proc Natl Acad Sci U S A 97: 12227-12232. doi:10.1073/pnas.220399597

Plantefaber LC, Hynes RO (1989) Changes in integrin receptors on oncogenically transformed cells. Cell 56: 281-290. doi:10.1016/00928674(89)90902-1

Prianichnikov N, Koch H, Koch S, Lubeck M, Heilig R, Brehmer S, Fischer R, Cox J (2020) Maxquant software for ion mobility enhanced shotgun proteomics. Mol Cell Proteomics 19: 1058-1069. doi:10.1074/ mcP.TIR119.001720

Pylayeva Y, Giancotti FG (2006) Development requires activation but not phosphorylation of beta1 integrins. Genes Dev 20: 1057-1060. doi:10.1101/gad.1432006

Rappsilber J, Mann M, Ishihama Y (2007) Protocol for micro-purification, enrichment, pre-fractionation and storage of peptides for proteomics using stagetips. Nat Protoc 2: 1896-1906. doi:10.1038/ nprot. 2007.261

Rehberg K, Kliche S, Madencioglu DA, Thiere M, Müller B, Meineke BM, Freund C, Budinger E, Stork O (2014) The serine/threonine kinase ndr2 controls integrin trafficking and integrin-dependent neurite growth. J Neurosci 34: 5342-5354. doi:10.1523/JNEUROSCI.2728-13.2014

Sakai T, Jove R, Fässler R, Mosher DF (2001) Role of the cytoplasmic tyrosines of beta 1a integrins in transformation by v-src. Proc Natl Acad Sci U S A 98: 3808-3813. doi:10.1073/pnas.240456398

Schneider CA, Rasband WS, Eliceiri KW (2012) Nih image to imagej: 25 years of image analysis. Nat Methods 9: 671-675. doi:10.1038/nmeth.2089

Schubert R, Strohmeyer N, Bharadwaj M, Ramanathan SP, Krieg M, Friedrichs J, Franz CM, Muller DJ (2014) Assay for characterizing the recovery of vertebrate cells for adhesion measurements by single-cell force spectroscopy. FEBS Lett 588: 3639-3648. doi:10.1016/j.febslet. 2014.06.012

Shiromizu T, Adachi J, Watanabe S, Murakami T, Kuga T, Muraoka S, Tomonaga $\mathrm{T}$ (2013) Identification of missing proteins in the nextprot database and unregistered phosphopeptides in the phosphositeplus database as part of the chromosome-centric human proteome project. J Proteome Res 12: 2414-2421. doi:10.1021/pr300825v

Suzuki K, Takahashi K (2003) Reduced cell adhesion during mitosis by threonine phosphorylation of beta1 integrin. J Cell Physiol 197: 297-305. doi:10.1002/jcp.10354

Takala H, Nurminen E, Nurmi SM, Aatonen M, Strandin T, Takatalo M, Kiema T, Gahmberg CG, Ylänne J, Fagerholm SC (2008) Beta2 integrin phosphorylation on thr758 acts as a molecular switch to regulate 143-3 and filamin binding. Blood 112: 1853-1862. doi:10.1182/ blood-200712-127795

Theodosiou M, Widmaier M, Böttcher RT, Rognoni E, Veelders M, Bharadwaj M, Lambacher A, Austen K, Müller DJ, Zent R, et al (2016) Kindlin-2 cooperates with talin to activate integrins and induces cell spreading by directly binding paxillin. Elife 5: e10130. doi:10.7554/ eLife.10130

Tseng HY, Samarelli AV, Kammerer P, Scholze S, Ziegler T, Immler R, Zent R, Sperandio M, Sanders CR, Fässler R, et al (2018) LCP1 preferentially 
binds clasped $\alpha \mathrm{M} \beta 2$ integrin and attenuates leukocyte adhesion under flow. J Cell Sci 131: jcs218214. doi:10.1242/jcs.218214

Wegener KL, Partridge AW, Han J, Pickford AR, Liddington RC, Ginsberg MH, Campbell ID (2007) Structural basis of integrin activation by talin. Cell 128: 171-182. doi:10.1016/j.cell.2006.10.048

Ye F, Petrich BG, Anekal P, Lefort CT, Kasirer-Friede A, Shattil SJ, Ruppert R, Moser M, Fässler R, Ginsberg MH (2013) The mechanism of kindlinmediated activation of integrin $\alpha \mathrm{llb} \beta 3$. Curr Biol 23: 2288-2295. doi:10.1016/j.cub.2013.09.050
Yu M, Strohmeyer N, Wang J, Müller DJ, Helenius J (2015) Increasing throughput of afm-based single cell adhesion measurements through multisubstrate surfaces. Beilstein I Nanotechnol 6: 157-166. doi:10.3762/bjnano.6.15

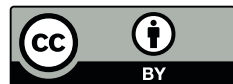

License: This article is available under a Creative Commons License (Attribution 4.0 International, as described at https://creativecommons.org/ licenses/by/4.0/). 